\title{
Effect of Ausforming on the Macro- and Micro-texture of Bainitic Microstructures
}

\author{
ADRIANA ERES-CASTELLANOS, LUCIA MORALES-RIVAS, \\ JOSE ANTONIO JIMENEZ, FRANCISCA G. CABALLERO, \\ and CARLOS GARCIA-MATEO
}

The reason why variant selection phenomena occur in ausforming treatments is still not known. For that reason, in this work, the effect of compressive deformation on the macro and micro-texture of a bainitic microstructure was analyzed in a medium-carbon high-silicon steel subjected to ausforming treatments, where deformation was applied at $520^{\circ} \mathrm{C}, 400{ }^{\circ} \mathrm{C}$ and 300 ${ }^{\circ} \mathrm{C}$. The as-received material presented a very weak $\langle 331\rangle$ fiber texture along the rod axis, due to prior thermomechanical processing. For the samples isothermally heat-treated, it was detected that the bainitic ferrite inherited a $\langle 100\rangle$ fiber texture from the $\langle 110\rangle$ fiber texture present in the prior austenite. The intensity of this transformation texture was more pronounced as the deformation temperature decreased. Also, variant selection was examined at different scales by combining Electron-Backscattered Diffraction and X-ray Diffraction. The quantification of the fraction of crystallographic variants under certain conventions for every condition revealed variant selection in samples subjected to ausforming treatments, where these phenomena were stronger as the deformation temperature was lower. Finally, some of the theories proposed so far to explain these variant selection phenomena were tested, showing that variants were not selected based on their Bain group and that their selection can be better described in terms of their belonging to packets, if these are defined according to a global reference frame. This suggests that the phenomena might have to do with the effect of deformation mechanisms on the prior austenite.

ADRIANA ERES-CASTELLANOS is with the Department of Physical Metallurgy, National Center for Metallurgical Research (CENIM-CSIC), Gregorio del amo, 8, 28040, Madrid, Spain and also with the Materials Testing, Technische Universität Kaiserslautern (TUK), Gottlieb-Daimler-Straße, 67663 Kaiserslautern, Germany. LUCIA MORALES-RIVAS is with the Materials Testing, Technische Universität Kaiserslautern (TUK). Contact e-mail: rivas@mv.uni-kl.de JOSE ANTONIO JIMENEZ, FRANCISCA G. CABALLERO, and CARLOS GARCIA-MATEO are with the Department of Physical Metallurgy, National Center for Metallurgical Research (CENIM-CSIC).

Manuscript submitted February 4, 2021; accepted June 15, 2021.

Article published online July 15, 2021 


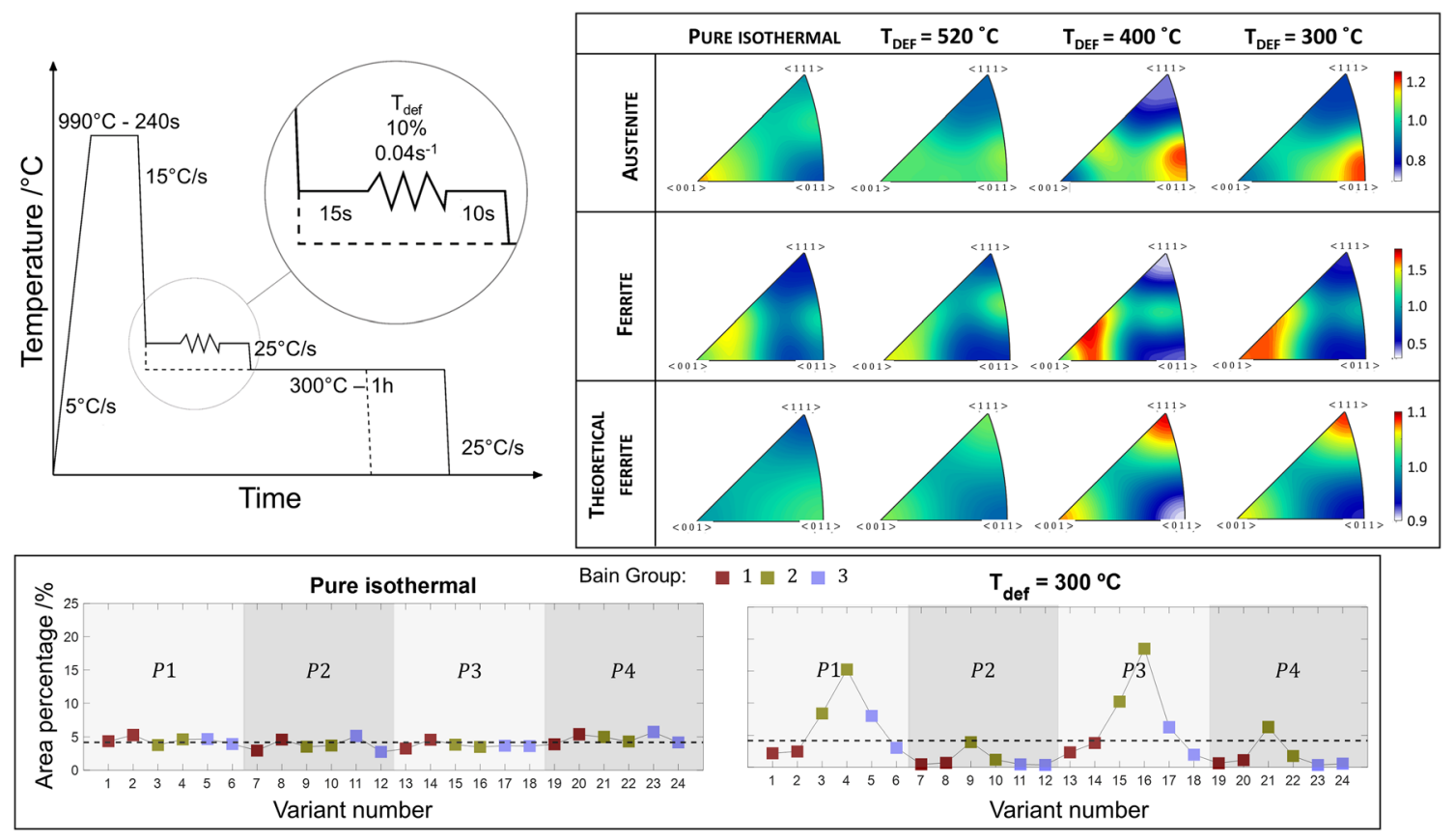

https://doi.org/10.1007/s11661-021-06363-w

(C) The Author(s) 2021

\section{INTRODUCTION}

DEFORMING austenite before the start of the bainitic reaction, by the so-called ausforming treatments, has been shown to lead to many benefits, including the acceleration of the bainitic transformation and the refinement of the microstructure ${ }^{[1-4]}$ However, this processing route is also associated with some microstructural changes that could be relevant to the properties of the material, such as the austenite mechanical stabilization, ${ }^{[5-7]}$ the formation of phases during the deformation step ${ }^{[8]}$ or the selection of crystallographic variants. ${ }^{[2,9-14]}$

Because bainitic transformations are displacive, the bainitic ferrite keeps a given orientation relationship (OR) with the prior austenite, characterized by the parallelism of planes and directions of the parent and the daughter phase. Usually, there are 3,12 or 24 bainitic ferrite orientations that form for a given prior austenite orientation, depending on the OR of the steel of study. The aggregates of parallel plates, also called sub-units and connected in three-dimensions, are named sheaves. From a purely crystallographic approach, based on the single-phase crystal orientation of bainitic ferrite, plates are grouped into blocks - groups of plates with the same crystallographic orientation - and packets-groups of blocks which share the same close-packed plane parallel relationship with austenite. Variant selection phenomena occur when not all the expected ferrite crystallographic orientations appear.
These phenomena have also been proven to affect the mechanical properties, as the final microstructure is less chaotic and the blocks and packets are coarser. ${ }^{[1]}$

Many authors have estimated the area percentage of variants in single PAGs ${ }^{[2,9,12-14]}$ in high-carbon steels subjected to isothermal treatments at low temperatures. Most of them have agreed on the fact that some variants were missing. ${ }^{[2,9,12,13]}$ Some of them also have tried to further describe the variant selection phenomena by studying its effect on macrotexture ${ }^{[9]}$ or by looking for trends regarding the belonging of the selected variants to specific Bain Groups (BGs) ${ }^{[12]}$ or Packets (Ps). ${ }^{[11]}$ Finally, few authors have tried to explain the mechanisms governing variant selection, claiming that they are associated with the dislocations ${ }^{[9,15]}$ or to residual stresses. ${ }^{[16,17]}$ Although these works have focused on the variant selection phenomenon, none of them have used statistical methods with large data to make their conclusions nor have extensively reviewed the literature, discussing about the relationship between their results and other results obtained by other authors on the same topic. Therefore, a general picture describing why variant selection occurs and how it affects both, the macro and micro-textures, is still lacking.

In the current work, the effect of the ausforming temperature on the final bainitic microstructure was studied in a medium-carbon $(\mathrm{C})$ silicon $(\mathrm{Si})$-rich steel, in terms of macro and micro-texture. The steel was the same as the one used in the previous work, ${ }^{[10]}$ in which strong variant selection phenomena had been detected, 
accompanied by an anisotropic dilatometric relative change in length signal along the radial and the longitudinal directions. The thermal and thermomechanical treatments of the mentioned work were replicated, intending to perform a more detailed characterization in terms of crystallography. To do so, the techniques of X-ray diffraction (XRD) and electron-backscattered diffraction (EBSD) were used. The variant selection phenomena were approached from a macro- and a micro-point of view, firstly studying how variant selection affects the macrotexture, then analyzing samples at the microscale. The study enabled to test some hypotheses that could explain the reason of the selection of crystallographic variants, drawing some conclusions about what its cause is.

\section{EXPERIMENTAL METHOD}

Dilatometry samples were machined from bars of the Sidenor's commercial steel SCM40 (0.4 wt pet C and 3 wt pct Si, among other alloying elements), which had been previously hot-rolled. Samples were machined so that their long axis was parallel to the rolling direction (RD), from now on called $Z$ axis. They were $10 \mathrm{~mm}$ long and their diameter was $4 \mathrm{~mm}$ (for the pure dilatometry treatments) or $5 \mathrm{~mm}$ (for the thermomechanical treatments). The dilatometer was a modified BAHR DIL 805A/D high-resolution quenching and deformation dilatometer, where tests were performed under high vacuum. This equipment uses an induction heating coil and blown He to control the heating and cooling steps during the test, with the assistance of a type $K$ thermocouple, welded on the surface of the specimen. Subsequently, samples were subjected to a pure isothermal treatment and to three different ausforming treatments, whose sketches are shown in Figure 1, accompanied by the abbreviations of the different phases present at each stage.

The as-received microstructure - microstructure Awas quenched and tempered, consisting of ferrite $(\alpha)$ and cementite $(\theta)$. After fully austenitizing the steel at $990{ }^{\circ} \mathrm{C}$ for 240 seconds, the microstructure was fully austenitic $(\gamma)$. Then, in the case of the pure isothermal treatment, $\gamma$ was cooled from $990{ }^{\circ} \mathrm{C}$ down to $300{ }^{\circ} \mathrm{C}$, cooling during which no phase transformation was detected. The microstructure obtained after such cooling - microstructure B - consisted of only $\gamma$. In the case of the ausforming treatments, after austenitization, $\gamma$ was cooled from $990{ }^{\circ} \mathrm{C}$ down to the deformation temperature $T_{\text {def }}$, which took the values of $520^{\circ} \mathrm{C}, 400{ }^{\circ} \mathrm{C}$ and $300^{\circ} \mathrm{C}$. No phase transformation was detected on those cooling steps either.

Then, samples were held at $T_{\text {def }}$ for 10 seconds, after which the compression step took place. All samples were deformed up to 10 pet at $0.04 \mathrm{~s}^{-1}$. In a previous work, in which the same steel and the same austenitization and deformation conditions were used, it was observed that bainite and martensite formed during the deformation steps at $400{ }^{\circ} \mathrm{C}$ and $300{ }^{\circ} \mathrm{C}$, respectively, induced by the energy introduced by the stress. ${ }^{[8]}$ The effect of these

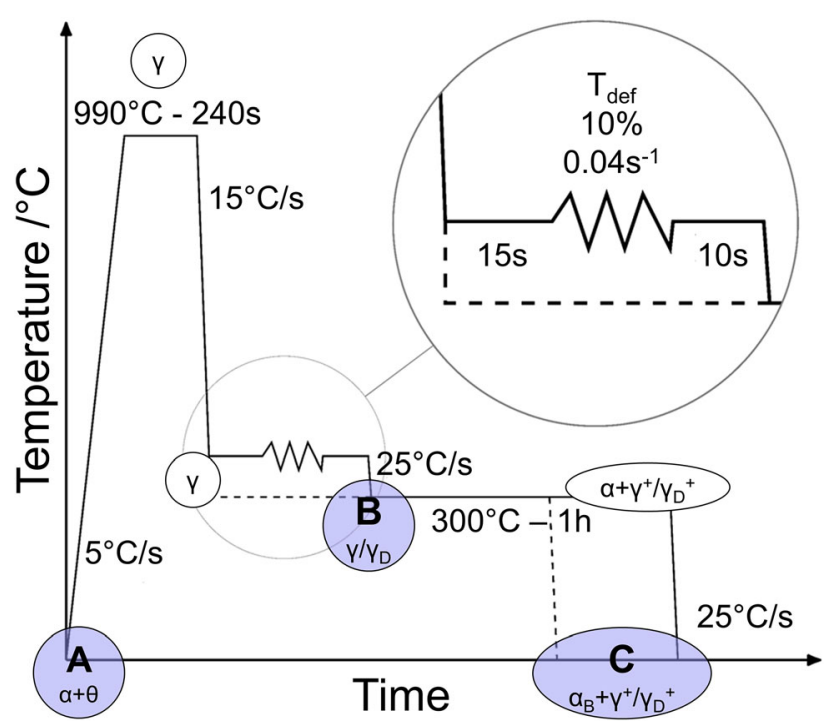

Fig. 1-Sketch of the thermal (dashed line) and thermomechanical (solid line) treatments performed in Ref. [10] and replicated in this work. $T_{\text {def }}$ stands for deformation temperature. The abbreviations of the different phases at each stage are indicated. The stages $\mathrm{A}, \mathrm{B}$, and $\mathrm{C}$ are described in the main text of the manuscript.

phases on the macro- and micro-textures of the final microstructures was considered negligible. After deforming the samples, the temperature was held for other 15 seconds, after which samples were cooled down to $300{ }^{\circ} \mathrm{C}$, stage during which no phase transformation was detected. Under the assumption previously made, the microstructures obtained after cooling-microstructures B-only consisted of deformed austenite $\left(\gamma_{\text {def }}\right)$. The so-called microstructures B are usually referred to as prior austenite in the literature.

Finally, regardless of the treatment, samples were held at $300{ }^{\circ} \mathrm{C}$ for 1 hour, holding stage during which the bainitic transformation occurred: bainitic ferrite $\left(\alpha_{\mathrm{B}}\right)$ plates grew supersaturated in carbon and, after their growth, they expelled carbon to the surrounding austenitic phase. After this holding, some high-carbon austenite $\left(\gamma^{+} / \gamma_{\text {def }}{ }^{+}\right)$remained in the microstructure, besides the formed $\alpha_{\mathrm{B}}$ plates. Samples were finally cooled down to room temperature, stage during which no martensitic transformation was detected. The final microstructures obtained at room temperature were called microstructures C. Further details on the dilatometry equipment and on the selection of the parameters describing those treatments can be found in Reference 10 .

The microstructures obtained by the described treatments were characterized by metallographic examination and by XRD and EBSD measurements. For those studies, the specimens were sectioned and polished following a conventional metallographic technique, including standard grinding with abrasive papers up to 2500 grid and a final polishing stage with $1 \mu \mathrm{m}$ diamond paste. Some polished specimens were etched with a 2 pct Nital (2 pet nitric acid in ethanol) solution and the revealed microstructures were analyzed by optical and scanning electron microscopy. The preparation 
procedure used for the samples subjected to EBSD and XRD measurements included etching and polishing cycles and a last polishing step with a $50 \mathrm{~nm}$ colloidal silica suspension, to remove any martensite that could have been formed during the grinding step by Transformation Induced Plasticity (TRIP) effect.

XRD measurements were performed by a Bruker AXS D8 X-ray diffractometer, with a Co X-ray tube working at $40 \mathrm{KV}$ and $30 \mathrm{~mA}$ in parallel-beam geometry and equipped with a LynxEye Linear Position Sensitive Detector. Conventional diffraction patterns were collected in Bragg-Brentano geometry, over a $2 \theta$ range of 45 to $135 \mathrm{deg}$, with a step size of $0.01 \mathrm{deg}$. These XRD profiles were analyzed for phase quantification and crystallographic information determination according to the Rietveld method, by using the 4.2 version of the program TOPAS (Bruker AXS). For this task, the instrumental functions were empirically parameterized from the diffraction pattern of a corundum sample. The mentioned diffractometer was also used to perform global texture measurements of $\alpha, \gamma^{+} / \gamma_{\text {def }}{ }^{+}$and $\alpha_{\mathrm{B}}$. To do so, three incomplete pole figures (PF) were measured in the back reflection mode, in the range of pole distance from 0 to $70 \mathrm{deg}$. The measured PF corresponded to planes (200), (2 111$)$ and (1 110$)$ for $\alpha ;(200),\left(2 \begin{array}{lll}2 & 1\end{array}\right)$ and (220) for $\alpha_{B}$; and (200), (220) and (311) for $\gamma^{+} / \gamma_{\text {def. }}$. Note that the mentioned $\alpha_{\mathrm{B}}$ and $\gamma^{+} / \gamma_{\text {def }}$ PF were selected to avoid the interference between the (1 111$)$ reflection of $\gamma^{+} / \gamma_{\text {def }}$ and the (1 110$)$ reflection of $\alpha_{\mathrm{B}}$, which cannot be separated at high tilt angles, when extensive peak broadening occurs due to defocusing effect. In all cases, the use of a collimator of $1 \mathrm{~mm}$ diameter and the a lineal detector centered at the $2 \theta$ position of these reflections enabled the collection of the whole diffracted intensity distributed over the angular range in the vicinity of the ideal focusing point. As the whole peak profile was covered at the ideal Bragg angle positions, the loss of intensity due to defocusing was compensated. On the other hand, the background contribution was eliminated using measurements taken far enough from the peak edge on the side of each reflection. From the experimental PF, the orientation distribution function (ODF, $f(g)$ ); was derived by the use of the Bunge's series expansion method and subsequently ghost corrected. ${ }^{[18]}$

Electron-backscattered diffraction (EBSD) measurements were performed by a Zeiss Auriga Compact FIB-SEM, operating at $20 \mathrm{kV}$, to study the bainitic microstructures. In all cases, $230 \times 173 \mu \mathrm{m}^{2}$ areas were scanned on the transverse section, using a step size of $0.35 \mu \mathrm{m}$. For all cases, only the $\alpha_{\mathrm{B}}$ (bcc) structure was considered, since $\gamma^{+}$(fcc) is mostly present as thin films, difficult to be correctly indexed.

The subsequent analyses of the XRD and the EBSD data were performed by means of MTEX, ${ }^{[19]} \mathrm{a} \mathrm{Matlab}^{\circledR}$ toolbox, and by the Channel 5 EBSD software (HKL Technology).

\section{RESULTS AND DISCUSSION}

In the following sections, the microstructures obtained by performing the described thermal and thermomechanical treatments, i.e., microstructures $\mathrm{C}$ in Figure 1, are studied in terms of macro and micro-texture. To do so, some aspects of the microstructure A (as-received microstructure) and the microstructures $\mathrm{B}\left(\gamma^{+} / \gamma_{\mathrm{def}^{+}}\right)$are also analyzed.

\section{A. Preliminary Microstructural Characterization and Macro-texture Analysis}

The aim of this subsection is to preliminary characterize microstructures $\mathrm{A}$ and $\mathrm{C}$, according to their microstructure (revealed by optical microscopy or scanning electron microscopy) and their volume percentages and global texture (measured by XRD).

Figure 2(a) shows the volume percentages of the different phases identified by XRD for microstructures $\mathrm{A}$ and $\mathrm{C}$. The as-received material, as mentioned, was quenched and tempered after hot rolling, Figure 2(b). It presents a completely globalized microstructure without residual lamellar pearlite colonies. This microstructure consists of fully recrystallized equiaxial grains of $\alpha$ and a large fraction of iron carbides $\theta$, both at grain boundaries and within grains. The volume percentages of $\alpha$ and $\theta$ were $95 \pm 3$ and $5 \pm 3$ pct, respectively. The bainitic microstructures, shown in Figure 2(c) through (f), obtained by either a pure isothermal treatment or by ausforming treatments, are composed of $\alpha_{\mathrm{B}}$ plates and $\gamma^{+} / \gamma_{\text {def }}{ }^{+}$thin films and blocks. The thin films lie between the $\alpha_{\mathrm{b}}$ plates, while blocks separate the $\alpha_{\mathrm{b}}$ sheaves. Carbides are not clearly visible in these microstructures, but its presence is restricted due to the high $\mathrm{Si}$ concentration in the alloy. The volume percentages of $\gamma^{+} / \gamma_{\text {def }}{ }^{+}$lay between $16 \pm 3$ and $26 \pm 3$ pct, according to XRD, being the $\gamma^{+} / \gamma_{\text {def }^{+}}$volume percentage lower as $T_{\text {def }}$ decreased, as reported elsewhere. ${ }^{[10]}$ The effect of ausforming on some crystallographic parameters (lattice parameters, tetragonality, crystallite size and microstrain) was also studied and it was shown that they barely changed with deformation.

Regarding the global texture, the as-received microstructure-microstructure $\mathrm{A}$ in Figure 1-was firstly studied. The as-received $\alpha$ global texture was measured by XRD and its most important texture components were identified. Figure 3 shows the ferrite texture in the as-received state and after the pure isothermal treatment. In this figure, the $\varphi_{2}=0 \mathrm{deg}$ and the $\varphi_{2}=45 \mathrm{deg}$ ODF sections are represented, where the Euler angles are in Bunge convention and the color scale is included in the right hand side. A schematic representation showing some common textures components is also included. It can be observed that both textures are very weak, since the maximum intensity of 
(a)
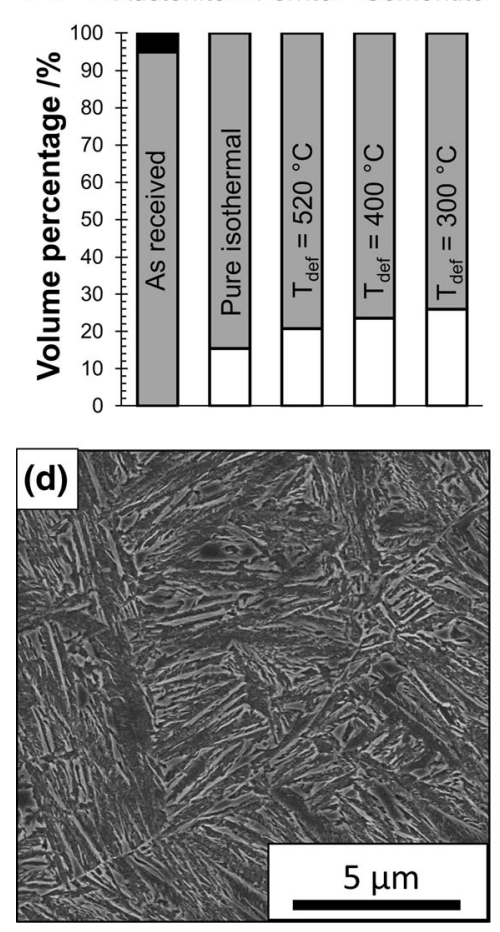
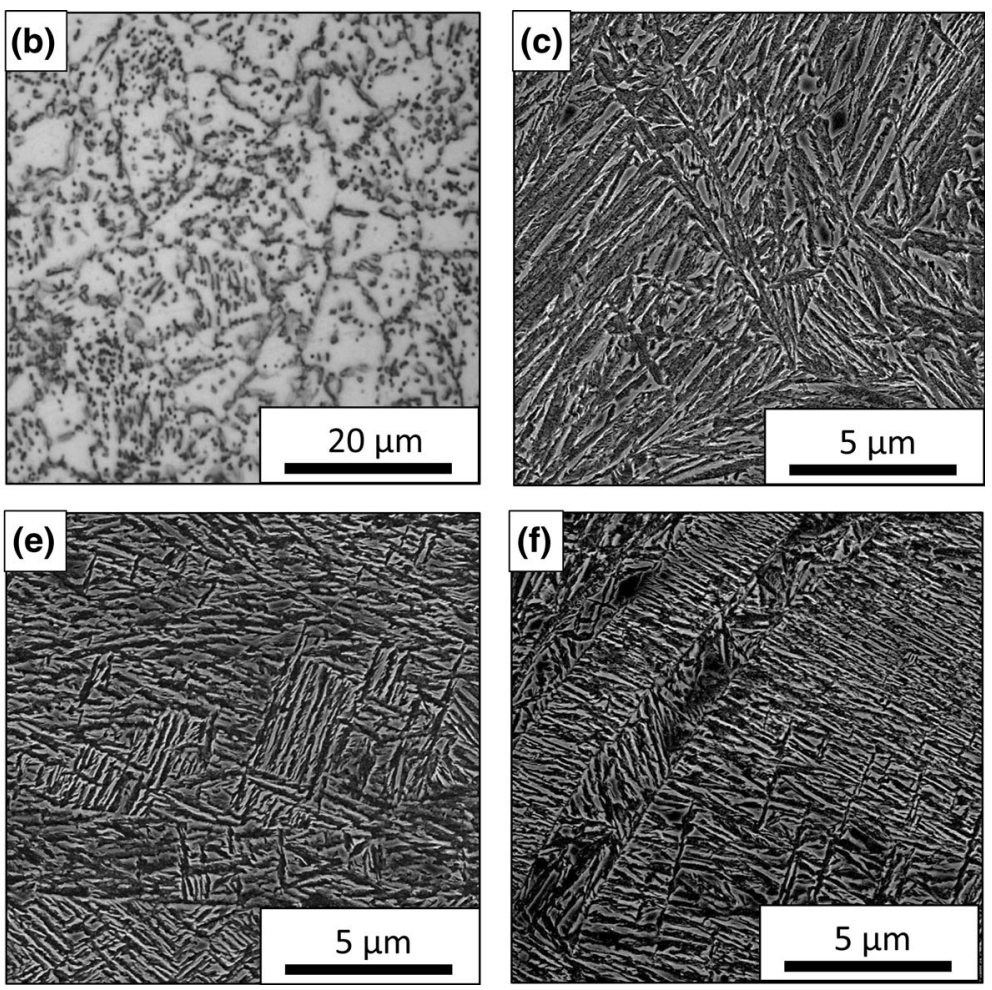

Fig. 2-(a) Volume fractions obtained by XRD for microstructures A and C (see Fig. 1); $(b$ to $f$ ) micrographs of the same microstructures: $(b)$ as-received microstructure; $(c)$ pure isothermal microstructure; $\left(d\right.$ to f) ausformed microstructures with $T_{\text {def }}$ equal to $(d) 520{ }^{\circ} \mathrm{C} ;(e) 400{ }^{\circ} \mathrm{C}$; and (f) $300^{\circ} \mathrm{C}$. All micrographs correspond to the longitudinal section, where the compression was applied (if applied) vertically.

the ODF is only 1.37 . The presence of a weak texture in the as-received material arises from a texture randomization, due to the austenite-ferrite transformation during the hot-rolling processing. Hence, as observed in Figure 3(a) and (b), the most important texture components in the as-received material are a $\langle 331\rangle$ fiber texture along the sample bar axis and some minor components of the $\langle 100\rangle$ fiber texture.

Secondly, the global texture of the phases present in the sample subjected to the pure isothermal treatment-microstructure $\mathrm{C}-$ were analyzed. The XRD $\gamma^{+}$global texture is shown in Figure 4(b), where it can be seen that there is some weak texture, characterized by two peaks around $\langle 001\rangle$ and $\langle 122\rangle$, where the former one is the most predominant component. This texture is similar to the one typically obtained in hot-rolled steel bars subjected to a bainitic transformation ("cylindrical" textures, formed by a mixture of a $\langle 001\rangle$ fiber and a

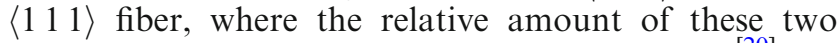
components depend on the stacking fault energy ${ }^{[20]}$ ).

The XRD $\alpha_{\mathrm{B}}$ global texture, although weak (see Figures 3(c) and (d) and 4(j)) is composed of two fibers: a $\langle 331\rangle$ fiber along the $\mathrm{Z}$ axis and a fiber texture which appears in all $\varphi_{2}$ sections on a line parallel to the $\varphi_{1}$ axis at $\phi$ angles in the range 10 to $15 \mathrm{deg}$. This fiber orientation represented a $\langle 100\rangle$ fiber separated 10 to 15 deg from the $Z$ axis. According to the Bain ${ }^{[21]}$ and Kurdjumov-Sachs ${ }^{[22]}$ OR, the $\left\{\begin{array}{llll}1 & 0 & 0\end{array}\right\}$ and $\left\{\begin{array}{lll}1 & 1 & 1\end{array}\right\}$ austenite planes align respectively with the $\left\{\begin{array}{lll}1 & 0 & 0\end{array}\right\}$ and $\left\{\begin{array}{lll}1 & 1 & 0\end{array}\right\}$ ferrite planes and, thus, it was expected that the effect of the $\gamma \rightarrow \alpha_{\mathrm{B}}$ phase transformation on the texture produced a mixture of $\langle 001\rangle$ and $\langle 110\rangle$ fiber textures, where the bainitic ferrite texture is weaker than the parent phase texture. However, the obtained texture is similar to the $\alpha$ global texture observed for the as-received state (see Figures 3(a) and (b) vs (c) and (d) and Figures 4(a) vs (j)). Texture inheritance phenomena have been observed in previous works in which the $\alpha_{\mathrm{B}}$ global texture was either completely preserved after austenitization ${ }^{[23,24]}$ or just weakened. ${ }^{[25,26]}$ These phenomena have been observed regardless of whether the initial material was bainitic/martensitic ${ }^{[23,25,27]}$ or pearlitic $^{[26]}$ and it has been proven that only austenitizations at high temperatures for prolonged times enable to suppress the memory effect. ${ }^{[28]}$ Especially, previous works by Castro Cerda et al. have elucidated the inheritance of $\alpha_{\mathrm{B}}$ global texture after treatments in which pearlitic microstructures were subjected to intercritical austenitization and subsequent quenching to form martensite. ${ }^{[2]}$ Castro Cerda et al. suggested that this phenomenon had to do with the oriented nucleation of $\gamma$ in the intercritical austenitization step, ${ }^{[27]}$ as the $\alpha_{\mathrm{B}}$ global texture differed more from the initial one as they increased the austenitization temperature and, in turn, the level of austenitization. However, as, mentioned, these phenomena have also observed in other fully austenitized steels which transformed to martensite and/ or bainite. ${ }^{[23,25]}$ The role of variant selection on the texture inheritance phenomena is studied in a subsequent section. 
(a) As-received, $\varphi_{2}=0^{\circ}$

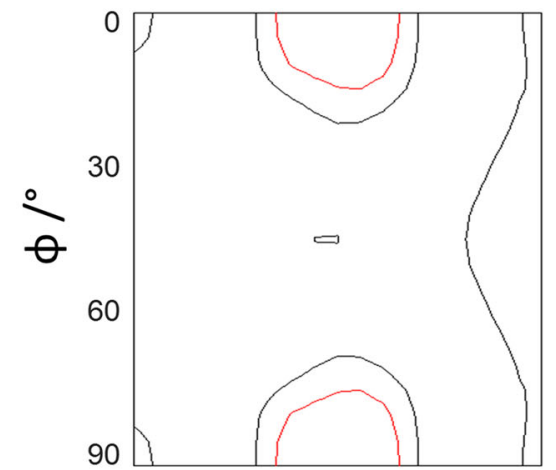

(c) Pure isothermal, $\varphi_{2}=0^{\circ}$

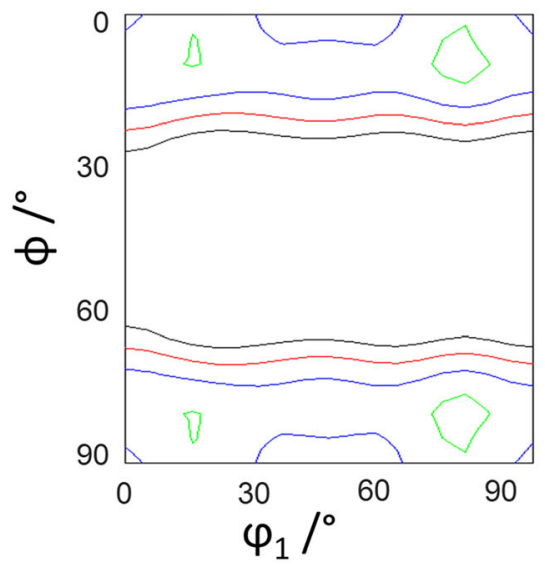

(b) As-received, $\varphi_{2}=45^{\circ}$

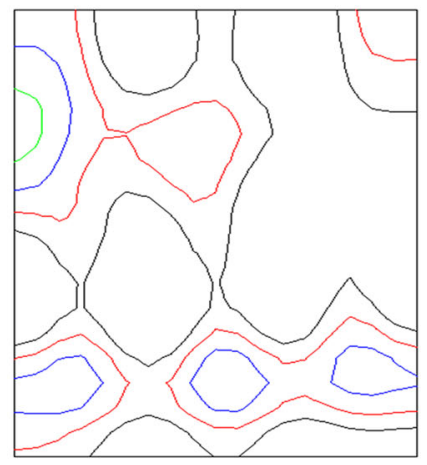

(d) Pure isothermal, $\varphi_{2}=45^{\circ}$

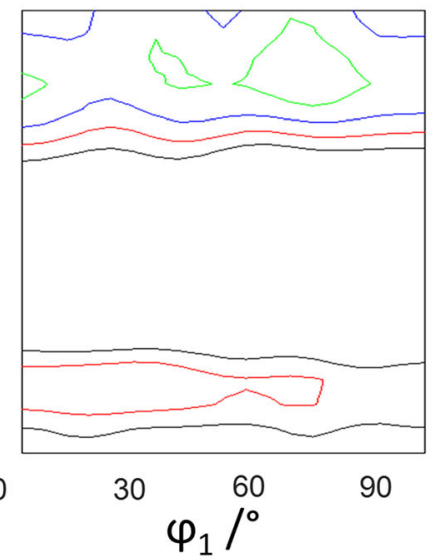

\section{$1.00 \square 1.10$}

1.20

1.30

(e) $\varphi_{2}=0^{\circ}$

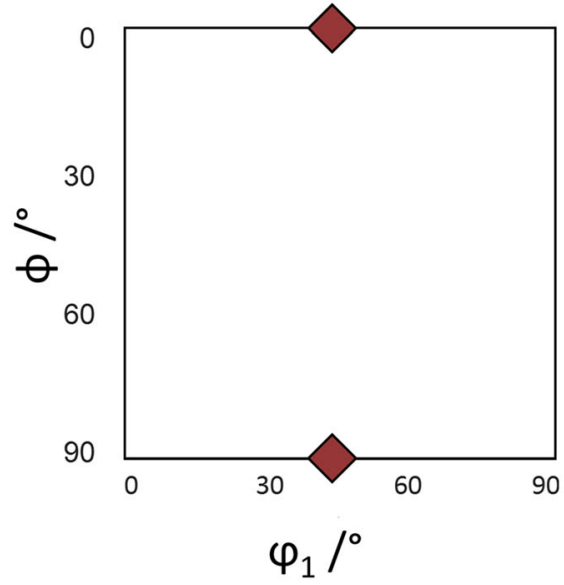

(f) $\varphi_{2}=45^{\circ}$

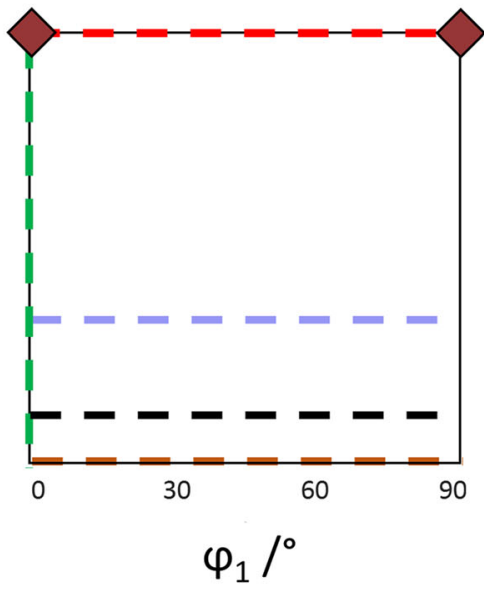

Fig. 3-ODF cuts at $\varphi_{2}=0 \mathrm{deg}$ and $\varphi_{2}=45 \mathrm{deg}$ for the ferrite in the $(a, b)$ as-received material and $(c, d)$ after the pure isothermal treatment. The MRD ranges for the as-received material and for the isothermally treated sample are 0.60 to 1.35 and 0.49 to 1.37 , respectively; $(e, f)$ Schematic representation of the $\varphi_{2}=0$ deg and the $\varphi_{2}=45$ deg sections of bcc ODF showing some common textures components. 
Finally, the global texture of the phases of the ausformed microstructures - microstructures $\mathrm{C}$-were studied. With regard to their $\gamma_{\text {def }}{ }^{+}$global texture, it can be seen that, considering the axial symmetry imposed by the macroscopic deformation, the samples exhibit a fiber texture with the compression axis as the fiber axis. This texture is stronger as $T_{\text {def }}$ decreases: the texture around $\langle 011\rangle$ and $\langle 114\rangle$ increases, whereas it decreases around $\langle 111\rangle$, see Figures 4(c) through (e). This texture is in good agreement with previous research on fcc materials subjected to uniaxial compression, with the $\langle 1110\rangle$ directions parallel to the sample bar axis.

The $\alpha_{\mathrm{B}}$ global texture varies as $T_{\text {def }}$ decreases, see Figures $4(\mathrm{k})$ through $(\mathrm{m})$. For the ausformed sample with $T_{\text {def }}=520{ }^{\circ} \mathrm{C}$, Figure $4(\mathrm{k})$, there is an intensity peak around $\langle 122\rangle$, besides scatter from $\langle 001\rangle$ to $\langle 113\rangle$, similar to the texture obtained for the pure isothermal treatment, see Figure 4(j). For lower $T_{\text {def }}$, the peak around $\langle 122\rangle$ becomes weaker, whereas the scatter from $\left\langle 0 \begin{array}{lll}0 & 1\rangle\end{array}\right\rangle$ to $\left\langle\begin{array}{llll}1 & 1 & 3\end{array}\right\rangle$ becomes more pronounced.

In this section, a microstructural characterization and a macro-texture analysis have been carried out. Some of the most important conclusions are: (a) the as-received microstructure consists of $\alpha$ and $\theta$, where the ferrite is slightly textured; (b) the austenitization step was not enough to remove the as-received texture completely, although the texture is weak; (c) the microstructures obtained by the pure isothermal treatment and the ausforming treatments are all bainitic, consisting of thin films and blocks of $\gamma^{+} / \gamma_{\text {def }}{ }^{+}$and $\alpha_{\mathrm{B}}$ plates. Regarding the texture of $\gamma^{+} / \gamma_{\text {def }}{ }^{+}$, it seems to be similar to the one expected according to the processing route, although the role of the bainitic transformation on the $\gamma^{+} / \gamma_{\text {def }}{ }^{+}$ texture will be deeply addressed in Section III-C. The texture of $\alpha_{\mathrm{B}}$ seems to be partially inherited from the as-received $\alpha$ texture. For the ausformed samples, the $\alpha_{\mathrm{B}}$ texture evolves as $T_{\text {def }}$ decreases.

\section{B. $\gamma / \gamma_{\text {def }}$ Reconstruction and $O R$ Determination}

The aim of this subsection is to reconstruct the microstructures B (see Figure 1), which only consisted of $\gamma / \gamma_{\text {def }}$, and to determine the OR between $\gamma / \gamma_{\text {def }}$ and $\alpha_{\mathrm{B}}$, corresponding to the isothermal treatment and the ausforming treatments. From these data, it is possible to study the effect of deformation on the shape of the prior austenite grains (PAGs) and to see what the effect of deformation on the OR is. Moreover, both, the reconstructed $\gamma / \gamma_{\text {def }}$ and the OR, are used in later subsections.

The $\gamma / \gamma_{\text {def }}$ were reconstructed from the $\alpha_{B}$ EBSD maps, corresponding to microstructures $\mathrm{C}$ in Figure 1.

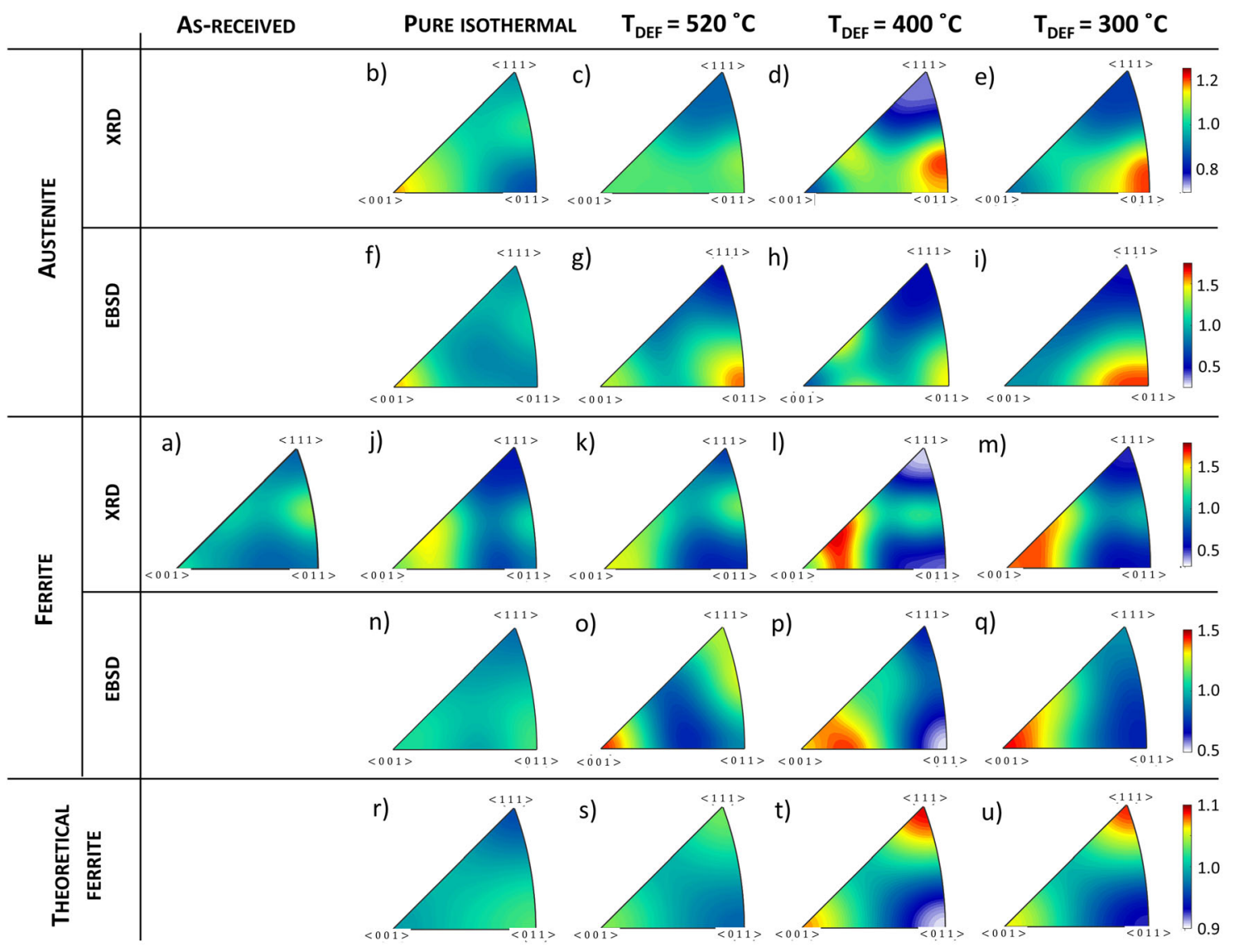

Fig. 4-Inverse Pole figures along the compression axis (IPFZ) obtained: (a) by XRD, corresponding to the as-received ferrite, $(b$ to $e$ and $j$ to $m$ ) by XRD; and ( $f$ to $i$ and $n$ to $q$ ) by selecting some areas of the EBSD maps for austenite $\left(\gamma^{+} / \gamma_{\text {def }}{ }^{+}\right.$, from a to d; and $\gamma / \gamma_{\text {def }}$, from $\mathrm{f}$ to $\left.\mathrm{m}\right)$ and for $\alpha_{\mathrm{B}}$ (j to q). The theoretical $\alpha_{\mathrm{B}}$ IPFZ obtained by applying the experimental OR to the XRD $\gamma / \gamma_{\text {def }}$ global texture is also shown $(r$ to $u$ ). Intensity in MRD (multiple of random density). 
The $\gamma / \gamma_{\text {def }}$ reconstruction can only be performed from martensitic or bainitic microstructures, which have a displacive nature, meaning that the bcc structure has a given correspondence with the fcc structure of the prior austenite grain (PAG) that it belongs to, the OR. Although reconstructive transformations also show an OR, this OR is given between bcc and adjacent PAGs and the reconstruction is, therefore, not possible. Different OR appears depending on the steel chemical composition and choosing the OR inaccurately could lead to error in the $\gamma / \gamma_{\text {def }}$ reconstruction. For that reason, different methodologies and pieces of software were tested to choose the one which presented the best results in terms of $\gamma / \gamma_{\text {def }}$ texture and PAG morphologies.

First of all, the piece of software Channel 5 was used to manually identify the PAGs, by making sure that the $\alpha_{\mathrm{B}}$ PF of the selected area consisted of certain single features that could be predicted by the theoretical OR. ${ }^{[2]}$ The data corresponding to each of the PAGs were exported to MATLAB $^{\circledR}$ to be analyzed by its toolbox MTEX. For every PAG, all possible parent orientations were calculated for every $\alpha_{\mathrm{B}}$ grain, assigning the most probable parent orientation to each grain. To make this calculation, the Greninger-Troiano (GT) OR, i.e., $\langle 0.120 .180 .98\rangle 44.26 \mathrm{deg},{ }^{[30]}$ previously observed in steels with similar carbon content as the one of this study, ${ }^{[31]}$ was assumed (and later corroborated).

The PAGs were automatically reconstructed by different pieces of software: ARPGE ${ }^{[32]}$; an in-house program; and PAG_GUI, a program developed by Nyyssönen et al. ${ }^{[33]}$ The comparison between the results obtained by the mentioned programs and by the manual reconstruction revealed that PAG_GUI is the most reliable option, as its reconstruction is the closest to the manual one in terms of grain morphology and local texture. The outstanding performance of the program PAG_GUI is mainly due to a prior stage implemented in the code for the determination of the experimental OR, which is achieved by refining the Kurdjumov-Sachs (KS) OR, i.e., $\langle 0.180 .180 .97\rangle 42.85$ deg. ${ }^{[22]}$ Therefore, all subsequent reconstructions were carried out by using PAG_GUI.

The experimental OR is extremely close regardless of the sample, see Table I; the maximum misorientation angle between all of them is $0.87 \mathrm{deg}$, which shows that the OR did not vary significantly because of the applied plastic deformation, in good agreement with previous studies. $^{[34]}$

The observed differences between the OR for the four samples can be explained based on the $\alpha_{\mathrm{B}}$ orientations scattering. Figure 5 shows the (110) PF of four randomly selected PAGs, each of them corresponding to one of the conditions. In each PF, the theoretical $\alpha_{\mathrm{B}}$ orientations, calculated by applying the corresponding OR to the reconstructed $\gamma / \gamma_{\text {def }}$ orientation, are depicted in black. As can be seen, for the pure isothermal condition, see Figure 5(a), most of the orientations are barely misoriented with respect to the theoretical orientation, i.e., the scattering is not pronounced, in good agreement with the assumption of the OR not changing with the $\gamma^{+} / \gamma_{\text {def }}{ }^{+}$carbon content during the transformation, as stated by Smith and Mehl. ${ }^{[35]}$ However, as $T_{\text {def }}$ decreases, see Figures $5(\mathrm{~b})$ through (d), the scattering is more noticeable, most likely because of the deformation in the lattice structure. ${ }^{[36]}$ In addition, some experimental variants seem to be missing, which would impair the optimization made by PAG_GUI. For that reason, from now on, the OR determined for the pure isothermal condition is assumed, as it is the most reliable one. This experimental OR is only misoriented by 0.27 deg with respect to the $\mathrm{GT}-\mathrm{OR}$, whereas the misorientation angles with the Nishiyama-Wassermann OR (NW-OR), i.e., $\langle 0.20 .080 .98\rangle \quad 45.98 \mathrm{deg}$ and the $\mathrm{KS}-\mathrm{OR}$ are 2.63 and $2.67 \mathrm{deg}$, respectively.

The reconstructed $\gamma / \gamma_{\text {def }}$ EBSD maps can be useful to evaluate the effect of deformation on the shape of the PAGs, by comparing their equivalent diameter (PAG$\mathrm{D}_{\mathrm{eq}}$ ) on the transverse section. Note that compressing $\gamma$ along the $Z$ axis ideally increases PAG-D eq $_{\text {, when }}$ measured on the transverse section. With that aim, PAGs were defined as regions within which the nearest neighbor (correlated) misorientation angle values were lower than 10 deg, i.e., PAG boundaries were defined by misorientation angles higher than $10 \mathrm{deg}$. For this analysis, all boundaries whose misorientation angles lay between 58 and $62 \mathrm{deg}$ were not considered as PAG boundaries but as annealing twins, since annealing twins are characterized by a $60 \mathrm{deg}$ misorientation about the

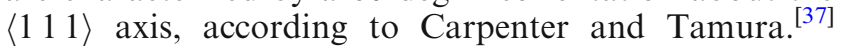
Figure 6 shows $\alpha_{\mathrm{B}}$ maps, displayed in $Z$ axis - inverse pole figure (IPF) coloring, where those two types of boundaries are shown. The equivalent diameter relative frequency histograms are superimposed on the maps and the calculated average PAG-D $\mathrm{D}_{\text {eq }}$ values corresponding to each sample can be found in Table I, by their standard deviations. As can be seen, the effect of the applied deformation on the value of PAG-D $D_{\text {eq }}$ is negligible, as all average values are similar, considering the associated error, and as the histograms are similar in terms of intensity and shape. Most likely, the applied plastic deformation (below 8.5 pct in all cases) was not high enough to lead to significant changes in the $\gamma_{\text {def }}$ microstructure in terms of morphology. Moreover, the value obtained for the pure isothermal condition is consistent with the one measured in Reference 10 by thermal etching in the same steel and for the same austenitization temperature, $18 \mu \mathrm{m}$.

As a summary, in this subsection, the $\gamma / \gamma_{\text {def }}$ EBSD maps (representative of microstructures B in Figure 1) were reconstructed from the EBSD maps of the bainitic microstructures (microstructures $\mathrm{C}$ in Figure 1) by using the piece of software PAG_GUI, which led to the best results and enabled to refine the OR. The next conclusions are drawn: (a) the OR does not change with deformation; small fluctuations are associated with the deformation in the lattice structure; (b) the steel OR was assumed to be the one obtained for the pure isothermal condition, as it is the one subjected to the lowest lattice deformation, i.e., $\langle 0.130 .180 .97\rangle 44.41 \mathrm{deg}$. This OR is only misoriented by $0.27 \mathrm{deg}$ with respect to the GT-OR and (c) the applied plastic deformation, always below 8.5 pct, was not high enough to lead to significant 
Table I. Data Obtained From the $\gamma / \gamma_{\text {def }}$ Reconstruction, Done by PAG_GUI, Where the Orientation Relationship (OR) is in Axis-Angle Convention and SD Stands for Standard Deviation

\begin{tabular}{lcr}
\hline Sample & OR & PAG-Deq \pm SD $(\mu \mathrm{m})$ \\
\hline Pure Isothermal & $\langle 0.130 .180 .97\rangle 44.41 \mathrm{deg}$ & $15.8 \pm 8.4$ \\
$T_{\text {def }}=520^{\circ} \mathrm{C}$ & $\langle 0.130 .180 .97\rangle 44.67 \mathrm{deg}$ & $14.2 \pm 7.3$ \\
$T_{\text {def }}=400^{\circ} \mathrm{C}$ & $\langle 0.120 .170 .98\rangle 44.76 \mathrm{deg}$ & $14.3 \pm 7.1$ \\
$T_{\text {def }}=300^{\circ} \mathrm{C}$ & $\langle 0.130 .160 .98\rangle 44.59 \mathrm{deg}$ & $14.2 \pm 8.9$ \\
\hline
\end{tabular}

The ausforming treatments can be identified by their deformation temperature $T_{\text {def. }}$.

(a)

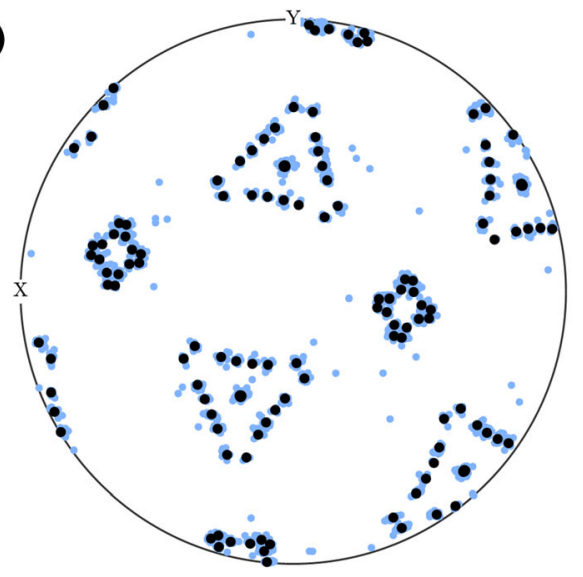

(c)

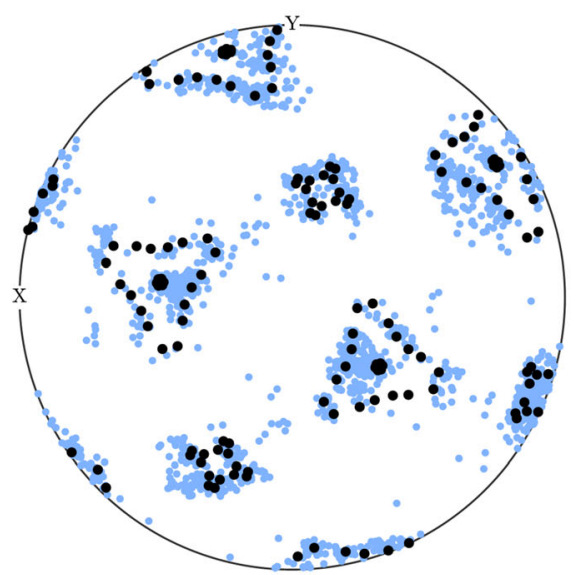

(b)

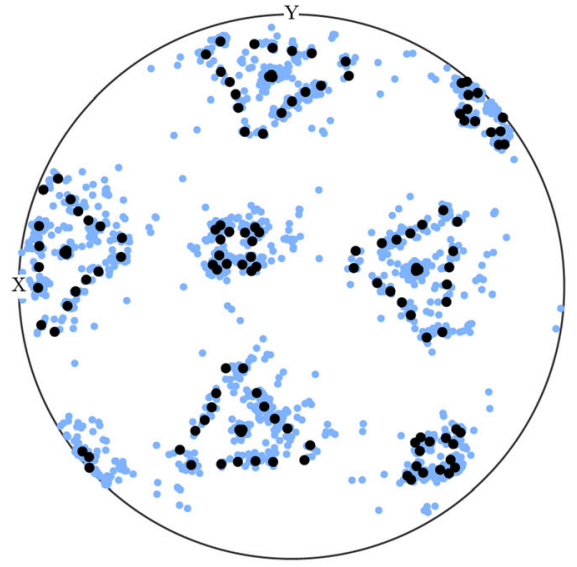

(d)

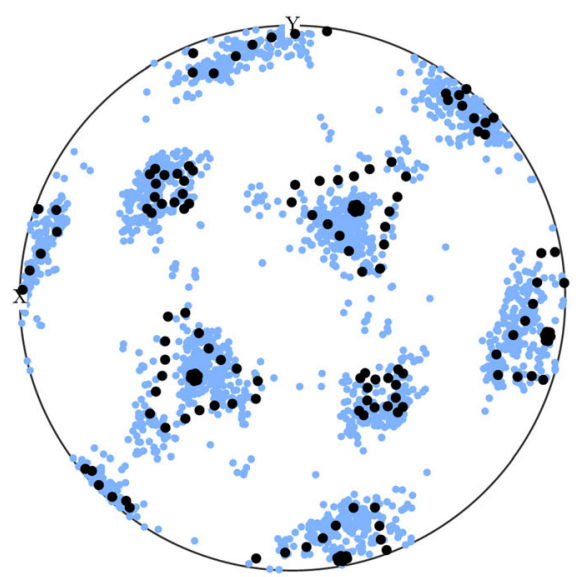

\section{Experimental $\alpha_{B}$ orientations}

\section{- Theoretical $\alpha_{\mathrm{B}}$ orientations according to the experimental OR}

Fig. 5- $\alpha_{\mathrm{B}}\left(\begin{array}{lll}1 & 1 & 0\end{array}\right)$ pole figures of randomly selected PAGs, where the blue circles are the experimental $\alpha_{\mathrm{B}}$ orientations and the black circles are the theoretical $\alpha_{\mathrm{B}}$ orientations for the corresponding PAG considering the corresponding experimental OR output by PAG GUI (close to the GT OR). Data correspond to: (a) pure isothermal treatment; (b) ausforming at $520{ }^{\circ} \mathrm{C} ;(c)$ ausforming at $400{ }^{\circ} \mathrm{C}$ and $(d)$ ausforming at $300{ }^{\circ} \mathrm{C}$ (Color figure online)

changes in the $\gamma_{\text {def }}$ microstructure in terms of morphology.

\section{Evolution of the Austenite Global Texture During} the Isothermal Step: Comparing $\gamma / \gamma_{\text {def }}$ to $\gamma^{+} / \gamma_{\text {def }}{ }^{+}$

When the study of the global texture of a given phase is aimed, reliable statistics are required. XRD is more appropriate than EBSD, since the latter measures the structure at the very surface of the sample. However, one question arises: whether it is correct to assume that the $\gamma^{+} / \gamma_{\text {def }}{ }^{+}$global texture obtained by XRD - global texture of the austenite present in microstructures $\mathrm{C}$ in Figure 1 -is statistically equivalent to the $\gamma / \gamma_{\text {def }}$ global texture-global texture of the austenite present in microstructures B in Figure 1. Although, in Section III-A., the texture of $\gamma^{+} / \gamma_{\text {def }}{ }^{+}$is apparently similar 

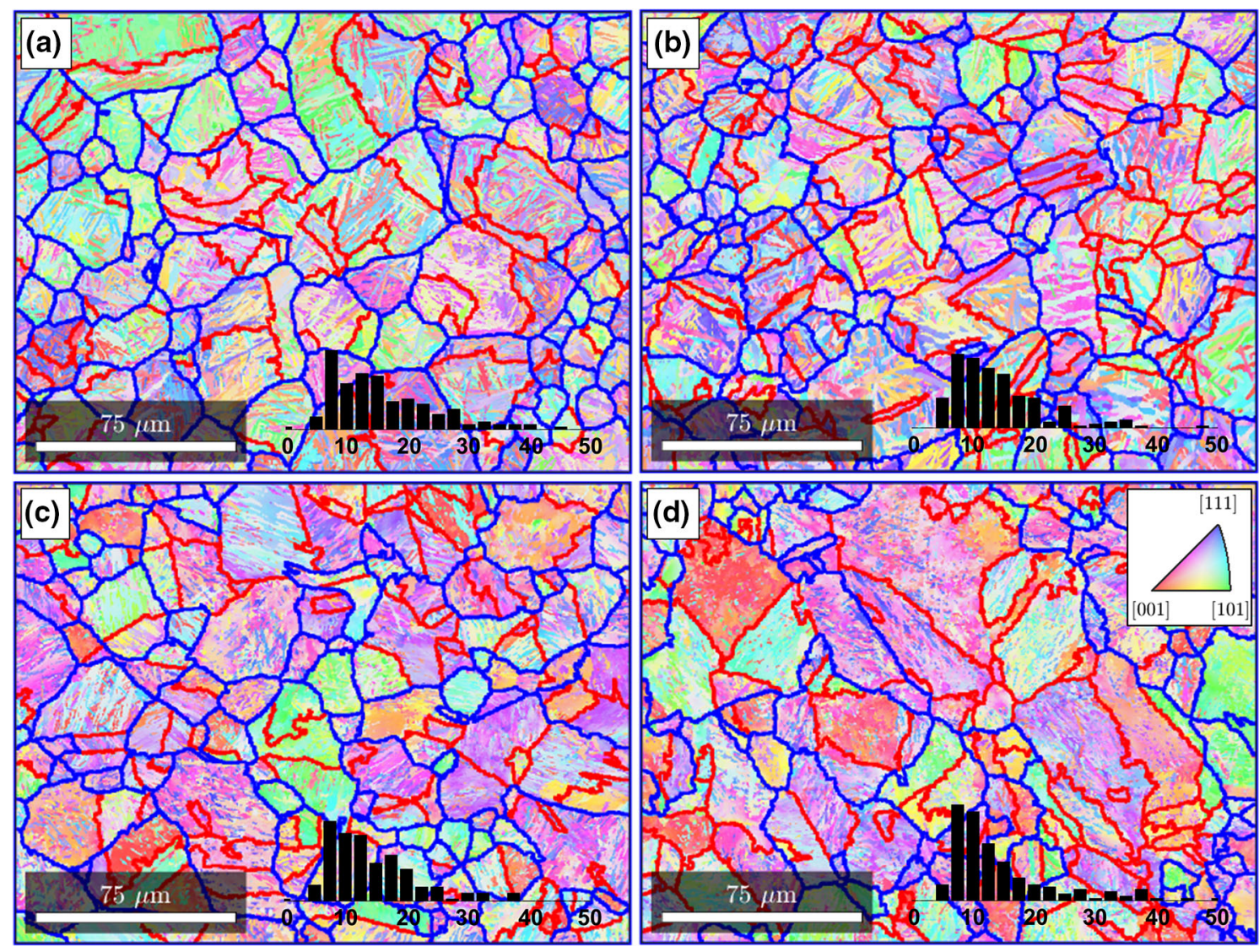

Fig. 6-Transverse $\alpha_{\mathrm{B}}$ IPF-Z maps, where the PAG boundaries, represented by blue lines, and the twin boundaries, represented by red lines, have been superimposed. Note that all pixels are indexed as the data has been subjected to noise reduction techniques for a cleaner representation. The maps correspond to (a) pure isothermally treated sample; $(b)$ ausformed sample with $T_{\text {def }}=520{ }^{\circ} \mathrm{C} ;(c)$ ausformed sample with $T_{\text {def }}=400{ }^{\circ} \mathrm{C}$; and $(d)$ ausformed sample with $T_{\text {def }}=300{ }^{\circ} \mathrm{C}$. The equivalent diameter relative frequency histograms are superimposed on the images, where the units of the horizontal axis are $\mu \mathrm{m}$ (Color figure online).

to the one expected according to the processing route, some discrepancies were found.

Present micro-segregation can make the austenite texture vary as the bainitic reaction progresses. In such a case, the $T_{0}$ curve, which indicates the carbon content for which the bainitic transformation should stop (and, thus, the volume fraction of $\alpha_{B}$ to form ${ }^{[38,39]}$ ), could locally vary. Hence, some PAGs could transform to a lower extent - they could have lower volume fractions of $\alpha_{B}$ - than other PAGs. This phenomenon would lead to a change in the $\gamma^{+} / \gamma_{\text {def }}{ }^{+}$global texture in comparison with the $\gamma / \gamma_{\text {def }}$ global texture, as the 'predominant' $\gamma^{+} /$ $\gamma_{\text {def }}{ }^{+}$orientations would correspond to the PAGs with the lowest carbon contents at $T_{0}$.

There are also some reasons why the austenite texture could change during the bainitic transformation in ausforming treatments. During the compression step, the deformation applied to the PAGs is inhomogeneous, because the plastic deformation that a PAG undergoes depends on the orientation of the slip system with respect to the deformation direction. ${ }^{[40]}$ As a consequence of the plastic deformation, $\gamma_{\text {def }}$ can get mechanically stabilized against bainitic transformation, ${ }^{[6,7]}$ therefore, it is reasonable to think that the PAGs with higher plastic deformations could have lower volume fractions of $\alpha_{\mathrm{B}}$ than other PAGs that have not undergone such a big plastic deformation. This phenomenon would lead to a change in the $\gamma_{\mathrm{def}^{+}}$global texture in comparison with the $\gamma_{\text {def }}$ global texture, as the "predominant' $\gamma_{\text {def }}{ }^{+}$orientations would correspond to the most mechanically stabilized PAGs. Such effects have been traditionally assumed to be negligible and both, $\gamma / \gamma_{\text {def }}$ and $\gamma^{+} / \gamma_{\text {def }^{+}}$global textures, have been assumed to be similar. ${ }^{[41,42]}$

In this subsection, the global textures of $\gamma / \gamma_{\text {def }}$ and $\gamma^{+} /$ $\gamma_{\text {def }}{ }^{+}$are compared in order to know whether they are equivalent or whether the austenite global texture evolves during the transformation. If it is proved that the austenite global texture does not vary during the bainitic transformation, the $\gamma^{+} / \gamma_{\text {def }}{ }^{+}$texture (which was obtained by XRD and is, thus, much more reliable) can be used as representative of $\gamma / \gamma_{\text {def }}$ in latter subsections which require a deeper analysis.

As mentioned, to confirm whether the mentioned assumption is correct or not, it is necessary to compare the global texture of $\gamma / \gamma_{\text {def }}$ to the $\gamma^{+} / \gamma_{\text {def }}{ }^{+}$global texture. Whereas the latter one was obtained by XRD, obtaining the former one is not straightforward by $\gamma$ reconstruction. The EBSD maps were shown not to be representative of the global microstructure, as the $\alpha_{\mathrm{B}}$ local 
texture obtained from them was not representative of the $\alpha_{\mathrm{B}}$ global texture obtained by XRD - a larger EBSD area should have been scanned. Therefore, to obtain the global $\gamma / \gamma_{\text {def }}$ textures, areas from the EBSD maps were selected in such a way so that their $\alpha_{B}$ local textures (EBSD) were similar to the $\alpha_{\mathrm{B}}$ global textures (XRD), see Figures 4(j) through $(\mathrm{m})$ vs $(\mathrm{n})$ through $(\mathrm{q})$. The $\gamma /$ $\gamma_{\text {def }}$ local textures of a selected area whose local $\alpha_{\mathrm{B}}$ texture was the same, or similar to, the global $\alpha_{B}$ texture can be assumed to be representative of the global $\gamma / \gamma_{\text {def }}$ texture too. The $\gamma / \gamma_{\text {def }}$ local textures of the selected EBSD areas, assumed to be equal to the $\gamma / \gamma_{\text {def }}$ global textures, are shown in Figures 4(f) through (i). If these $\gamma /$ $\gamma_{\text {def }}$ global textures are compared to the XRD $\gamma^{+} / \gamma_{\text {def }}{ }^{+}$ global textures, see Figure 4(b) through (e) vs (f) through (i), it can be proved that the global texture of the $\gamma_{\text {def }}$ phase remained unchanged during the transformation. Note that differences in terms of intensity can be due to the different resolutions of the applied techniques: XRD enables to obtain a better picture of the $\gamma^{+} / \gamma_{\text {def }}{ }^{+}$ texture, whereas resolution limitations of the EBSD technique or $\gamma / \gamma_{\text {def }}$ reconstruction errors could lead to lower texture intensities. Therefore, the discrepancies shown in Section III-A with respect to the expected textures could be due to small inhomogeneities during the hot-rolling process which made the as-received texture not to be exactly the expected one.

In this section, it was proved that the austenite global texture was not modified during the bainitic transformation, regardless of whether it was previously plastically deformed or not. Hence, in the next section, whose aim is to study the global texture of $\gamma / \gamma_{\text {def }}$ and $\alpha_{B}$, only $\mathrm{XRD}$ data are used, as their reliability is much higher than the one of EBSD in this matter.

\section{Variant Selection Analysis}

\section{Qualitative study of variant selection}

The aim of this section is to qualitatively assess the phenomenon of variant selection by using XRD diffraction measurements, once it was proved that the global texture of both $\gamma / \gamma_{\text {def }}$ austenite belonging to microstructures $\mathrm{B}$ in Figure 1 -is equivalent to the global texture of $\gamma^{+} / \gamma_{\text {def }}^{+}$in microstructures $\mathbf{C}$ in Figure 1, see Section III-C.

Firstly, in Section III-A., it was shown that the global texture of $\alpha_{\mathrm{B}}$ in the pure isothermal specimen resembled the one of $\alpha$ in the as-received material. The role of the $\gamma$ texture on the $\alpha_{\mathrm{B}}$ texture was studied by calculating the expected $\alpha_{\mathrm{B}}$ global texture under no variant selection conditions, by applying the experimental OR to the corresponding XRD $\gamma^{+}$global texture and forcing all possible crystal orientations of $\alpha_{\mathrm{B}}$ to be equally probable. The so-calculated textures are referred to as theoretical $\alpha_{\mathrm{B}}$ global textures from now on. The experimental vs. theoretical $\alpha_{B}$ global textures can be found in Figure 4(j) and (r), respectively. While, as mentioned, the experimental XRD $\alpha_{\mathrm{B}}$ global texture is characterized by two peaks around the directions $\langle 133\rangle$ and $\langle 001\rangle$, the theoretical $\alpha_{\mathrm{B}}$ global texture has its maximum intensity around the $\left\langle\begin{array}{llll}0 & 1 & 1\end{array}\right\rangle$; and besides, its lowest intensity can be found around $\langle 111\rangle$. This comparison proves that the transformation occurred anisotropically, although probably not very pronounced, based on the low texture intensities. In a previous study, Bhadeshia et al. ${ }^{[43]}$ also found out that samples isothermally treated at different temperatures present anisotropic behaviors in terms of the dilatations observed during the isothermal holding, i.e., samples were not expanding in the same amount along the radial and the longitudinal directions, i.e., isotropic. These results were replicated in the current study and, although the dilatation along the transversal direction was only slightly longer than the dilatation along the rolling direction, they were different. Bhadeshia et al. ${ }^{[43]}$ explained that this behavior had to be forcedly accompanied by a variant selection event, as an isotropic transformation could not lead to differences in dimensional changes, even though the parent austenite was textured. The reason given for the observed changes was that $\gamma$ texture favored the nucleation of specific $\alpha_{B}$ variants. The results of the present work support this hypothesis, showing its link with the inheritance of the $\alpha_{\mathrm{B}}$ global texture.

Lastly, the role of the $\gamma_{\text {def }}$ global texture on the bainitic transformation in the ausformed samples was also studied by calculating the theoretical $\alpha_{B}$ global textures in the same way as for the pure isothermal treatment, see Figures 4(s) through (u). It can be seen that the experimental $\alpha_{\mathrm{B}}$ global texture of the sample ausformed at the highest temperature is the only one similar to the theoretical one, which proves that there is a macroscopic variant selection effect governing at least the remaining phase transformations, especially for the ausforming treatment with $T_{\text {def. }}=400{ }^{\circ} \mathrm{C}$. This is in good agreement with the results by Gong et al. ${ }^{[9]}$ where differences in the $\alpha_{\mathrm{B}}$ global texture after an ausforming treatment with respect to the theoretical one were also observed for a high-carbon bainitic steel. These results also agree with the ones obtained in Reference 10, which showed a positive intensity of the dimensional changes in length $v s$ time, obtained during the isothermal holding of the ausforming treatment at $520^{\circ} \mathrm{C}$; whereas negative intensities were obtained for the two other $T_{\text {def, }}$, where the effect was more pronounced in the case of $T_{\text {def. }}=$ $400{ }^{\circ} \mathrm{C}$. Although the ausforming treatment with $T_{\text {def. }}=$ $300{ }^{\circ} \mathrm{C}$ was expected to have both the lowest signal and the strongest variant selection, the possible formation of martensite during the compression step might have affected the bainitic transformation, as reported in Reference 8 .

In this section, the phenomenon of variant selection was qualitatively addressed. Some of the drawn conclusions are: (a) for the pure isothermal treatment, the $\alpha_{\mathrm{B}}$ global texture cannot be explained by the observed $\gamma / \gamma^{+}$global texture and has to be associated with variant selection effects; and (b) the measured $\alpha_{\mathrm{B}}$ global texture in ausformed specimens only can be explained by the observed $\gamma_{\mathrm{D}} / \gamma_{\mathrm{D}}{ }^{+}$global texture in the case of the ausforming at $520{ }^{\circ} \mathrm{C}$, whereas the $\alpha_{\mathrm{B}}$ global texture observed in the specimens ausformed at $400{ }^{\circ} \mathrm{C}$ and $300{ }^{\circ} \mathrm{C}$ cannot be explained by the observed $\gamma_{\mathrm{D}} /$ $\gamma_{\mathrm{D}}{ }^{+}$global texture, phenomenon linked to variant selection. 


\section{Micro-texture analysis and quantitative study} of variant selection

In this section, variant selection is approached from a quantitative point of view. The microstructures obtained by the pure isothermal treatment and the ausforming treatments - microstructures $\mathrm{C}$ in Figure 1 -were further analyzed by using the EBSD areas selected in Section III-C, which are representative of every condition. Statistically, the number of variants in the PAGs of every condition and the area that they occupied were estimated to know which treatment is associated with the most severe variant selection. Using this approach enables to study variant selection independently, not having to choose any convention related to the global system.

To quantify variant selection, selected areas of the EBSD maps were divided into MTEX $\alpha_{B}$ grains. A MTEX $\alpha_{B}$ grain was defined as a group of pixels with neighbor-to-neighbor misorientation angle below $3 \mathrm{deg}$. Lower misorientations than $3 \mathrm{deg}$ were not considered as they correspond to local misorientations, i.e., small misorientations due to deformation within the same crystallographic sub-block. By comparing the crystallographic orientation of a given $\alpha_{B}$ grain to the $\gamma / \gamma_{\text {def }}$ orientation of its corresponding $\mathrm{PAG}$, it is possible to identify its crystallographic variant. In order to use a common convention for any PAG, each $\gamma / \gamma_{\text {def }}$ orientation was substituted by its crystallographic equivalent for which the $Z$-axis was contained in the triangle delimited by the crystal directions [0 [0 0 l 1$]-\left[\begin{array}{lll}1 & 1 & 1\end{array}\right]-\left[\begin{array}{lll}0 & 1 & 1\end{array}\right]$. The reason lying beneath this convention is discussed in a latter section. Table II shows the 24 crystallographic variants of the experimentally estimated OR, besides the set of planes and directions that must fulfill parallelism and the groups of variants that form a block (B), a P and a BG.

For every $i$ th variant $(V i)$, belonging to a $j$ th PAG $\left(P A G_{-} j\right)$, its area $\left(A_{V i, j}\right)$ was determined as the summation of the area of all the blocks in $P A G_{-} j$. The area percentage of each variant $\left(A P_{V i, j}\right)$ relative to the area of $P A G_{-} j\left(A_{P A G_{-} j}\right)$ was calculated as:

$$
A P_{V i, j}=\frac{A_{V i, j}}{A_{P A G_{-j} j}} \cdot 100
$$

A PAG which is not governed by any variant selection effect should ideally have 24 variants, each with the same area $A P_{V i, j}$, i.e., 4.2 pct. In each PAG, the $n$ variants whose area $A P_{V i, j}$ exceed 4.2 pct are named predominant variants from now on. A sample with strong variant selection should present a small average $n$, i.e., there are few variants that are predominant, accompanied by an increase of the average area of any predominant variant. In this way, even though there are few variants with a larger $A P_{V i, j}$ than $4.2 \mathrm{pct}$, those variants occupy most part of the PAGs. Figures 7(a), (c), (e), (g) shows histograms of the number of predominant variants $n$ in a PAG, i.e., the relative frequency $\mathrm{RF}_{n}$ vs $n$; where $\mathrm{RF}_{n}$ was defined as:

$$
\mathrm{RF}_{n}=N_{n} / N_{t} \times 100
$$

$N_{n}$ is the number of PAGs with $n$ predominant variants; and $N_{t}$ is the total number of analyzed PAGs. Figures 7(b), (d), (f), (h) depicts the histograms of the area of the most predominant variant in a $\mathrm{PAG}$, i.e., the relative frequency $\mathrm{RF}_{\mathrm{AP}_{V-\text { max }, j}}$ vs $\mathrm{AP}_{V-\max , j}$, where $\mathrm{RF}_{\mathrm{AP}_{V-\max , j}}$ and $\mathrm{AP}_{V-\max , j}$ were defined by Eqs. [3] and [4]. $N_{n 1}$ is the number of PAGs whose most predominant variant area is $\mathrm{AP}_{V-\max , j}$.

$$
\begin{gathered}
\mathrm{RF}_{\mathrm{AP}_{V-\max , j}}=N_{n 1} / N_{t} \times 100 \\
\mathrm{AP}_{V-\max , j}=\max \left\{\left(\mathrm{AP}_{V i, j}\right)_{i=1 \ldots 24}\right\}
\end{gathered}
$$

Although only the histograms corresponding to $\mathrm{AP}_{V-\max , j}$ are shown in this work, the trend for any other predominant variant follows the same behavior as explained below.

It can be seen that a certain degree of variant selection is already found even for the pure isothermal treatment, see Figures 7(a) and (b), as most of the PAGs have 8 predominant variants and the most predominant one has, on average, about a 20 pct of the total PAG area, in good agreement with the results obtained in Section III-D-A. Regarding the ausforming treatments, variant selection is stronger as $T_{\text {def }}$ decreases, since there are less predominant variants that take most of the area percentage, see Figures 7(c) through (h), i.e., few variants occupy most the PAG area. These results are in good agreement with previous works, which reported variant selection by estimating the area percentage of variants in single PAGs. ${ }^{[2,9,12,13]}$

The present results indicate that the variant selection phenomenon observed in the ausformed samples is a product of two different mechanisms and that they affect global texture in a different way. The first of the mechanisms is the one that controls the transformation during the pure isothermal treatment and is dependent on the as-received global texture. However, the second type of mechanisms depends on the plastic deformation applied during the compression stage in ausforming treatments. As already discussed in Section III-D-A., no effect of variant selection on the global texture was detected for the sample ausformed at $520{ }^{\circ} \mathrm{C}$, which suggests that both effects were cancelled out at the macroscopic scale. For deformations applied at lower temperatures, the effect of the plastic deformation predominates over the global texture memory effect.

Therefore, in this section it is concluded that all the microstructures, obtained after conducting either the pure isothermal or the ausforming treatments, $-\mathrm{C}$ in Figure 1-show variant selection. This conclusion was met after statistically studying how many variants are 
Table II. Experimental OR Variants, Showing the Parallel Planes and Directions Correspondence

\begin{tabular}{|c|c|c|c|c|c|}
\hline \multirow[b]{2}{*}{ Packet } & \multirow[b]{2}{*}{ Block. } & \multirow[b]{2}{*}{ Variant } & \multirow[b]{2}{*}{ Bain Group } & \multicolumn{2}{|c|}{ OR Parallelism } \\
\hline & & & & Parallel Planes & Parallel Directions \\
\hline \multirow[t]{6}{*}{$P 1$} & \multirow[t]{2}{*}{$B 1$} & $V 1$ & \multirow[t]{2}{*}{ BG1 } & \multirow{6}{*}{$\left(\begin{array}{llll}1 & 1 & 1\end{array}\right)_{\gamma} / /(0.0031 .2521 .24)_{\alpha_{B}}$} & {$\left[\begin{array}{ll}17 \overline{5} & \overline{12}\end{array}\right]_{\gamma} / /[\overline{0.442} 1.636 \overline{1.652}]_{0}$} \\
\hline & & $V 2$ & & & {$\left[\begin{array}{lll}17 \overline{12} & \overline{5}\end{array}\right] / / /\left[\begin{array}{lll}\overline{0.442} & \overline{1.636} & 1.652\end{array}\right]$} \\
\hline & \multirow[t]{2}{*}{$B 2$} & $V 3$ & \multirow[t]{2}{*}{ BG2 } & & 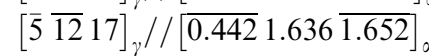 \\
\hline & & $V 4$ & & & {$\left[\begin{array}{lll}\overline{12} & \overline{5} & 17\end{array}\right]_{\gamma} / /[\overline{0.442} \overline{1.636} 1.652]$} \\
\hline & \multirow[t]{2}{*}{$B 3$} & $V 5$ & \multirow[t]{2}{*}{ BG3 } & & 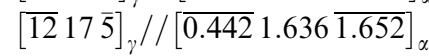 \\
\hline & & $V 6$ & & & {$\left[\begin{array}{ll}5 & 17 \overline{12}\end{array}\right]_{\gamma} / /[\overline{0.442} \overline{1.636} 1.652] 。$} \\
\hline \multirow[t]{6}{*}{$P 2$} & \multirow[t]{2}{*}{$B 4$} & $V 7$ & \multirow[t]{2}{*}{ BG1 } & \multirow[t]{6}{*}{$(1 \overline{1} 1)_{\gamma} / /(0.0031 .2521 .24)_{\alpha_{B}}$} & {$\left[\begin{array}{lll}17 & 5 & 12\end{array}\right]_{\gamma} / /[\overline{0.442} \overline{1.636} 1.652]$} \\
\hline & & $V 8$ & & & {$[\overline{17} \overline{12} 5]_{\gamma} / /[\overline{0.442} 1.636 \overline{1.652}]_{0}$} \\
\hline & \multirow[t]{2}{*}{ B5 } & $V 9$ & \multirow[t]{2}{*}{ BG2 } & & {$[5 \overline{12} \overline{17}]_{\gamma} / /[\overline{0.442} \overline{1.636} 1.652]_{0}$} \\
\hline & & $V 10$ & & & {$\left[\begin{array}{lll}12 \overline{5} & \overline{17}\end{array}\right]_{\gamma} / /[\overline{0.442} 1.636 \overline{1.652}]$} \\
\hline & \multirow[t]{2}{*}{$B 6$} & $V 11$ & \multirow[t]{2}{*}{ BG3 } & & {$\left[\begin{array}{lll}12 & 17 & 5\end{array}\right]_{\gamma} / /\left[\begin{array}{lll}0.442 & \overline{1.636} & 1.652\end{array}\right]_{\alpha}$} \\
\hline & & $V 12$ & & & {$\left[\begin{array}{lll}5 & 17 & 12\end{array}\right]_{,} / /[\overline{0.442} 1.636 \overline{1.652}]$} \\
\hline \multirow[t]{6}{*}{$P 3$} & \multirow[t]{2}{*}{$B 7$} & $V 13$ & \multirow[t]{2}{*}{ BG1 } & \multirow[t]{6}{*}{$\left(\begin{array}{lll}1 & 1 & 1\end{array}\right)_{\gamma} / /\left(\begin{array}{llll}0.003 & 1.252 & 1.24\end{array}\right)_{\alpha_{B}}$} & {$\left[\begin{array}{lll}17 & 512\end{array}\right]_{\gamma} / /\left[\begin{array}{lll}0.442 & 1.636 & 1.652\end{array}\right]_{\alpha}$} \\
\hline & & $V 14$ & & & 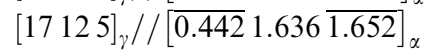 \\
\hline & \multirow[t]{2}{*}{$B 8$} & $V 15$ & \multirow[t]{2}{*}{ BG2 } & & {$\left[\begin{array}{lll}5 & 12 & \overline{17}\end{array}\right]_{\gamma} / /[\overline{0.442} \overline{1.636} 1.652]$} \\
\hline & & $V 16$ & & & $\left.[\overline{12} 5 \overline{17}]_{\gamma} / / / \overline{0.442} 1.636 \overline{1.652}\right]_{\alpha}$ \\
\hline & \multirow[t]{2}{*}{$B 9$} & $V 17$ & \multirow[t]{2}{*}{ BG3 } & & {$\left[\begin{array}{lll}12 & \overline{17} & 5\end{array}\right]_{\gamma} / /[\overline{0.442} \overline{1.636} 1.652]$} \\
\hline & & $V 18$ & & & 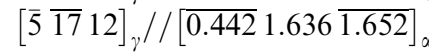 \\
\hline \multirow[t]{6}{*}{$P 4$} & \multirow[t]{2}{*}{$B 10$} & $V 19$ & \multirow[t]{2}{*}{ BG1 } & \multirow[t]{6}{*}{$\left(\begin{array}{lll}1 & 1 & \overline{1}\end{array}\right)_{\gamma} / /(0.0031 .2521 .24)_{\alpha_{B}}$} & {$[\overline{17} 5 \overline{12}]_{\gamma} / /[\overline{0.442} \overline{1.636} 1.652]_{0}$} \\
\hline & & $V 20$ & & & {$[\overline{17} 12 \overline{5}]_{\gamma} / /[\overline{0.442} 1.636 \overline{1.652}]_{\alpha}$} \\
\hline & $B 11$ & $V 21$ & BG2 & & 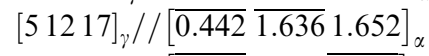 \\
\hline & & $V 22$ & & & {$\left[\begin{array}{lll}12 & 5 & 17\end{array}\right]_{\gamma} / /[\overline{0.442} 1.636 \overline{1.652}]_{\alpha}$} \\
\hline & $B 12$ & $V 23$ & BG3 & & 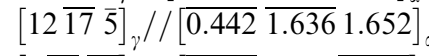 \\
\hline & & $V 24$ & & & {$\left[\begin{array}{ll}5 \overline{17} & 12\end{array}\right]_{\gamma} / /[\overline{0.442} 1.636 \overline{1.652}]_{\alpha}$} \\
\hline
\end{tabular}

present in the PAGs of all microstructures and how much area they are taking from the corresponding PAG area. In addition, this conclusion agrees with many authors who quantified variant selection by estimating the area percentage of variants in single PAGs. ${ }^{[2,9,12,13]}$ Results prove that variant selection occurred even when prior deformation was not applied, although it became stronger as deformation was applied at a lower $T_{\text {def }}$. The results also suggest that there are two types of mechanisms affecting variant selection: the ones that are related to the texture inheritance phenomenon explained in Section III-D-A, which explain why variant selection is found for the pure isothermal condition, and those related to the applied plastic deformation. The lower $T_{\text {def }}$ is, the more predominant the latter mechanisms are over the former ones. This is the reason why no effect variant selection on the global texture was detected for the sample ausformed at $520{ }^{\circ} \mathrm{C}$, see Section III-D-A.

\section{E. Theories on the Variant Selection Phenomenon in Ausformed Samples}

In this section, some of the variant selection theories described in the literature for the formation of bainite under ausforming conditions are discussed. Although, as mentioned, those models apply for transformations occurred during ausforming treatments, for the sake of discussion and trends, results are also compared with the ones obtained for the pure isothermal treatment.

Some authors have suggested that, for ausforming treatments, the selected variants belong to the same $\mathrm{BG}^{[12]}$ or to the same $\mathrm{P},{ }^{[11]}$ whereas others suggest that the variant selection phenomenon is associated with the formation of dislocations during the deformation stage. In this case, each variant would correspond to a specific slip system and the variants whose associated SS contained a higher amount of dislocations would appear more frequently. ${ }^{[15]}$ All premises are tested in the following paragraphs. 


\section{Pure isothermal}
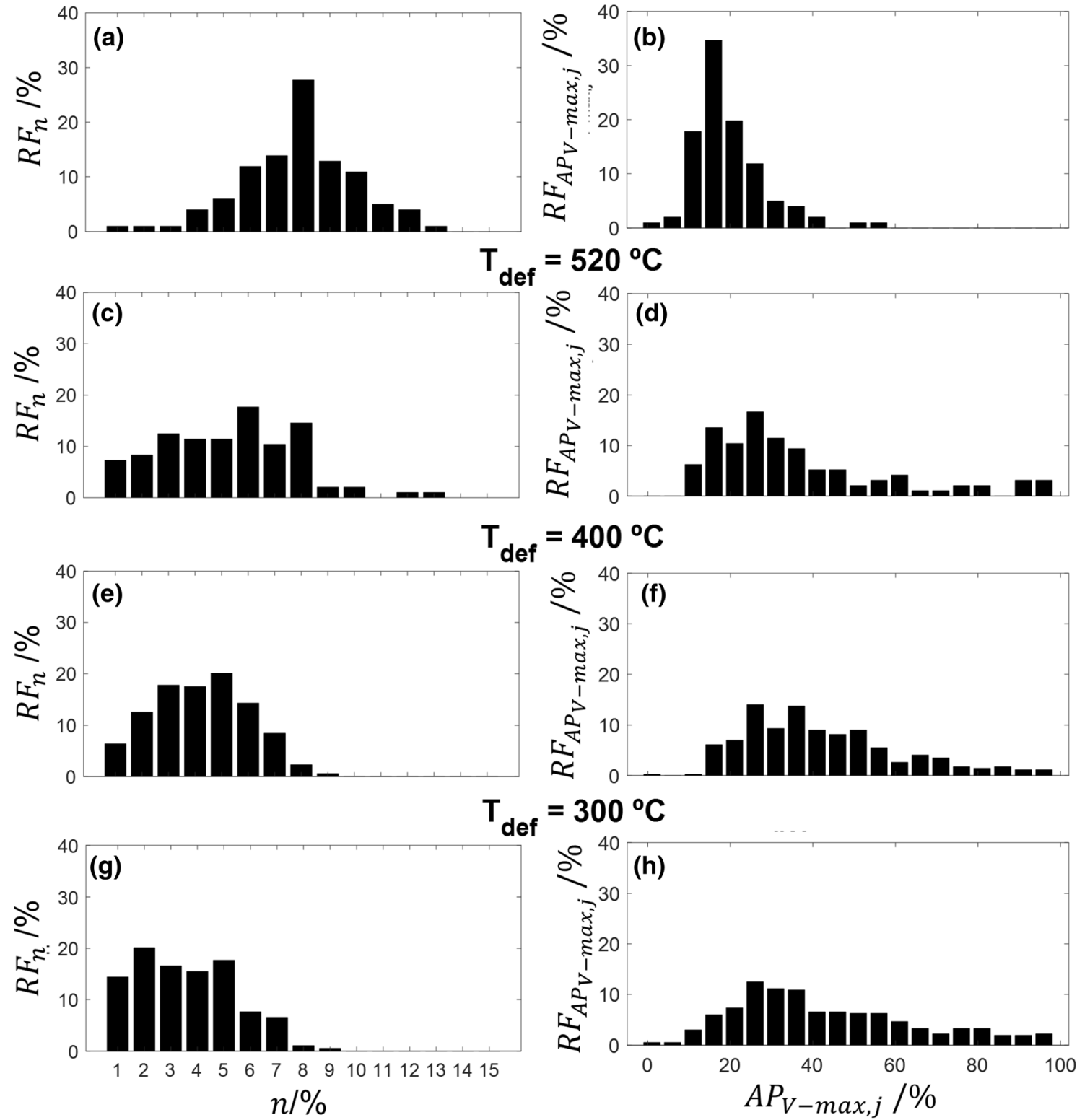

Fig. 7-Histograms from $\alpha_{\mathrm{B}}$ EBSD maps representative of the global texture showing $(a, c, e, g) \mathrm{RF}_{n} v s \quad n$ and $\left(b, d\right.$, f, h) $\mathrm{RF}_{\mathrm{AP}} v_{V-\max , j} v s$ $\mathrm{AP}_{V-\text { max }, j}$. Variables are defined in the main text. Data corresponds to: (a, b) a pure isothermal treatment; (c, d) an ausforming treatment with $T_{\text {def }}=520{ }^{\circ} \mathrm{C}$; (e, f) an ausforming treatment with $T_{\text {def }}=400{ }^{\circ} \mathrm{C}$ and $(\mathrm{g}, \mathrm{h})$ an ausforming treatment with $T_{\text {def }}=300{ }^{\circ} \mathrm{C}$.

\section{Relationship among the observed variants}

In order to test the first premise- the selected variants belong to the same $\mathrm{BG},{ }^{[12]}$ variants were numbered as explained. First, for each PAG, BGs were arranged according to their area percentage $\left(\mathrm{AP}_{\mathrm{BG} k, j}\right)$ in descending order. Then, within each $\mathrm{BG}$, the corresponding variants were arranged according to their $\mathrm{AP}_{V i, j}$ in descending order. Under such a convention, variant 1 is the most frequent variant belonging to the $\mathrm{BG}$ with the largest $\mathrm{AP}_{\mathrm{BG} k, j}$, variant 2 is the second most frequent variant from the $\mathrm{BG}$ with the largest $\mathrm{AP}_{\mathrm{BG} k, j}$, and so on. Each $\mathrm{BG}$ and each variant under such an order are referred to as $\mathrm{BG} k_{\mathrm{BG}}$ and $V i_{\mathrm{BG}}$, respectively. Therefore, the area percentage of the $k_{\mathrm{BG}}$ th $\mathrm{BG}$ in the $j$ th PAG is
$\mathrm{AP}_{\mathrm{BG} k_{\mathrm{BG}}, j}$ and the area percentage of the $i_{\mathrm{BG}}$ th variant in the $j$ th PAG is $\mathrm{AP}_{V i_{\mathrm{BG}}, j}$. The average area percentages of the variants, considering all PAGs from the selected EBSD maps, where variant numbers $\left(i_{\mathrm{BG}}\right)$ were assigned as explained before $\left(\mathrm{AP}_{V i_{\mathrm{BG}}}\right)$, were calculated by Eq. [5]. Additionally, the average area percentages of the three $\mathrm{BG} k_{\mathrm{BG}}\left(\mathrm{AP}_{\mathrm{BG} k_{\mathrm{BG}}}\right)$ were calculated by using Eq. [6].

$$
\begin{aligned}
\mathrm{AP}_{V i_{\mathrm{BG}}} & =\frac{\sum_{j=1}^{N_{t}} \mathrm{AP}_{V i_{\mathrm{BG}} j}}{N_{t}} \\
\mathrm{AP}_{\mathrm{BG} k_{\mathrm{BG}}} & =\frac{\sum_{j=1}^{N_{t}} A P_{\mathrm{BG} k_{\mathrm{BG}} j}}{N_{t}}
\end{aligned}
$$


(b)
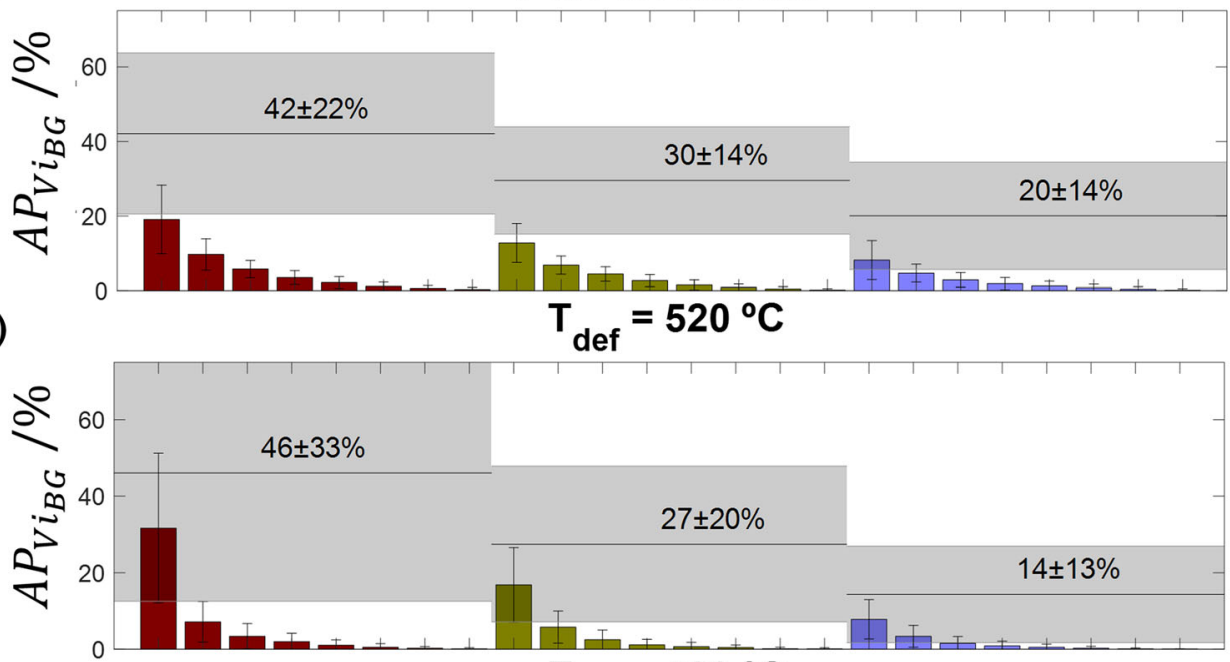

(c)

$\mathrm{T}_{\mathrm{def}}=400^{\circ} \mathrm{C}$
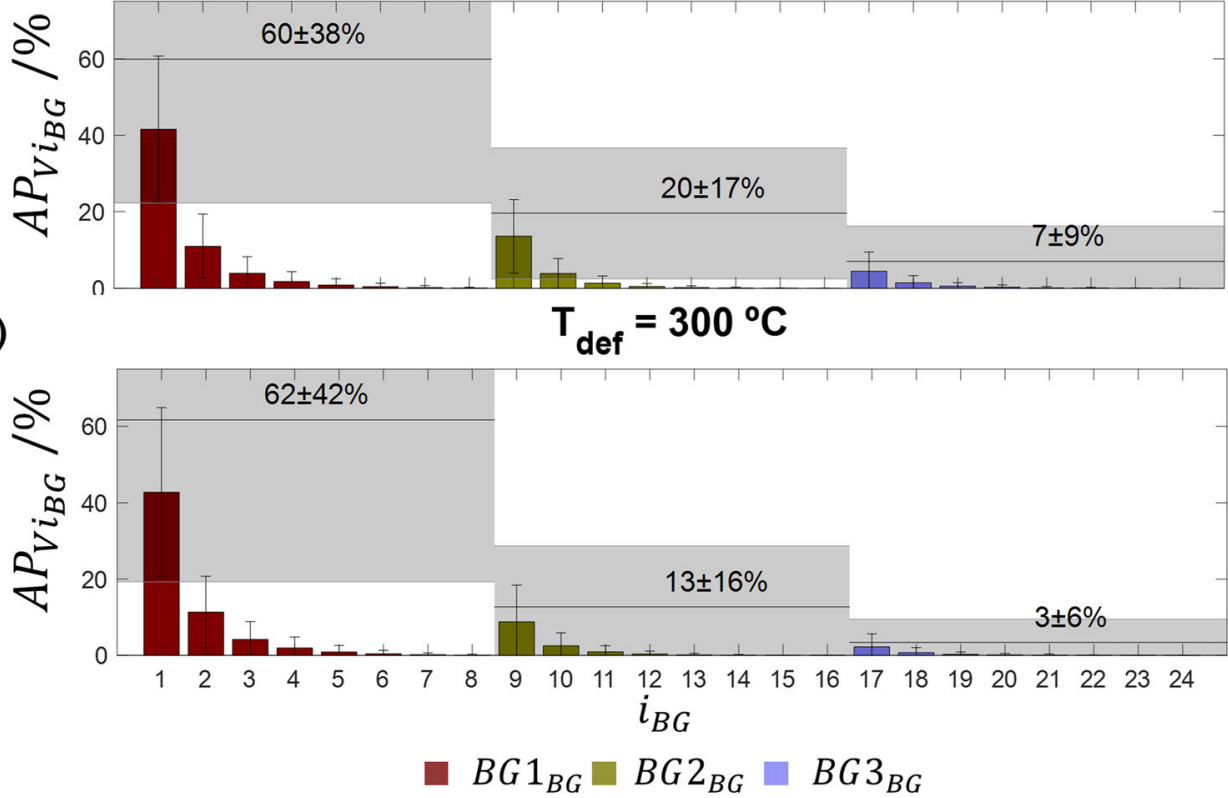

Fig. 8- Bar plots of $\mathrm{AP}_{V i_{\mathrm{BG}}}$ vs $i_{\mathrm{BG}}$. The error bars are the corresponding standard deviations and the bar color changes depending on the $B G_{B G}$ to which the variant belongs. Data correspond to: $(a)$ pure isothermal treatment; $(b)$ ausforming at $520{ }^{\circ} \mathrm{C} ;(c)$ ausforming at $400{ }^{\circ} \mathrm{C}$ and $(d)$ ausforming at $300{ }^{\circ} \mathrm{C}$. The three horizontal lines depict $\mathrm{AP}_{\mathrm{BG} k_{\mathrm{BG}}}$, which is written on top of them, followed by their standard deviations. The variables have been defined in the main text.

While $\mathrm{AP}_{V i_{\mathrm{BG}}}$ can be found in Figure 8 as a function of $i_{\mathrm{BG}}$ by their standard deviations, $\mathrm{AP}_{\mathrm{BG} k_{\mathrm{BG}}}$ are depicted in the same figure by horizontal lines. It can be observed that variants with the highest area percentages $\left(\mathrm{AP}_{V 1_{\mathrm{BG}}}, \mathrm{AP}_{V 9_{\mathrm{BG}}}\right.$ and $\left.\mathrm{AP}_{V 17_{\mathrm{BG}}}\right)$ do not belong to the same $B G$, but they are present in all three BGs. It is worth noting that the difference between $\mathrm{AP}_{\mathrm{BG}} 1_{\mathrm{BG}}$ and $\mathrm{AP}_{\mathrm{BG} 3_{\mathrm{BG}}}$ increases as $T_{\text {def }}$ decreases, owing to a larger value of $\mathrm{AP}_{V i_{\mathrm{BG}}}$ for the most predominant variant in every $\mathrm{BG} k_{\mathrm{BG}}\left(V 1_{\mathrm{BG}}, V 9_{\mathrm{BG}}\right.$ and $\left.V 17_{\mathrm{BG}}\right)$, as discussed in Section III-D-A, whereas $\mathrm{AP}_{V i_{\mathrm{BG}}}$ values for other $V i_{\mathrm{BG}}$ in the $\mathrm{BG} k_{\mathrm{BG}}$ remain similar. The theory suggested by
He et al. ${ }^{[12]}$ found a different trend in a high-carbon high-silicon steel subjected to ausforming treatments at $T_{\text {def }}=300{ }^{\circ} \mathrm{C}$, same temperature at which the isothermal treatment for bainitic transformation took place. In that work, all variants belonging to the predominant BGs contributed to the area percentage supremacy of the corresponding $\mathrm{BG}$, unlike it was observed in the present work.

The second premise is based on Miyamoto et al.'s work ${ }^{[11]}$ who performed ausforming treatments in a low-alloy low-carbon steel. In that work the deformation steps at $700{ }^{\circ} \mathrm{C}$ were followed by quenching or a 
(a)

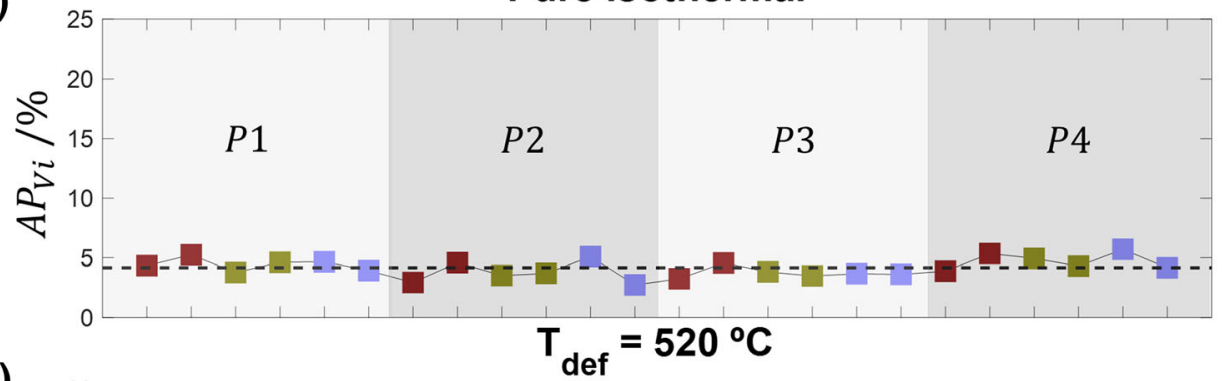

(b)

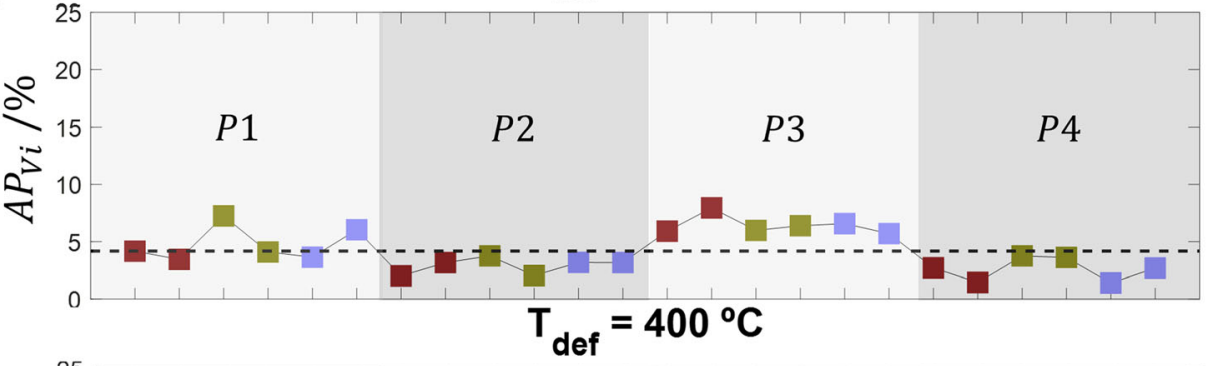

(c)

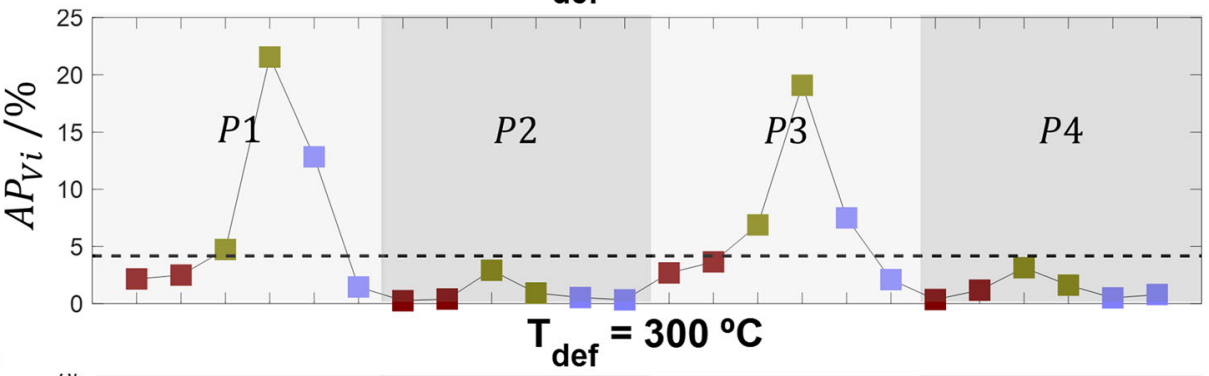

(d)

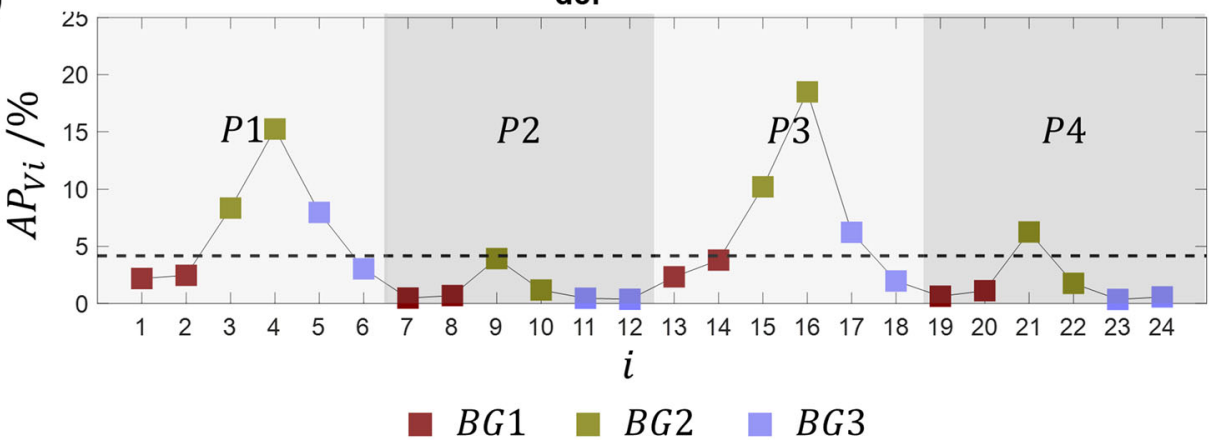

Fig. 9- $\mathrm{AP}_{V i}$ of variant $i$ formed by $(a)$ a pure isothermal treatment; $(b)$ an ausforming treatment with $T_{\text {def }}=520{ }^{\circ} \mathrm{C}$; $(c)$ an ausforming treatment with $T_{\text {def }}=400{ }^{\circ} \mathrm{C}$ and $(d)$ an ausforming treatment with $T_{\text {def }}=300{ }^{\circ} \mathrm{C}$. Dashed lines represent the area percentage that would be expected without variant selection. The grey areas show which packets the variants belong to, whereas the marker colors change depending on the BG to which the variant belongs (Color figure online).

pure isothermal holding at $400{ }^{\circ} \mathrm{C}$, obtaining martensitic or bainitic structures, respectively. Miyamoto showed that variants showing the parallelism $\left(\begin{array}{lll}1 & 1 & 1\end{array}\right) / /\left\{\begin{array}{lll}0 & 1 & 1\end{array}\right\}$ or $(\overline{1} 11) / /\left\{\begin{array}{lll}0 & 1 & 1\end{array}\right\}$ and, thus, belonging to P1 or P3 (see Table II), were more prone to appear. In that work, to identify the variants, they indexed the austenite orientations so that the $\mathrm{Z}$-axis was contained in the triangle delimited by the directions $\left[\begin{array}{lll}0 & 0 & 1\end{array}\right]-\left[\begin{array}{lll}1 & 1 & 1\end{array}\right]-\left[\begin{array}{lll}0 & 1 & 1\end{array}\right]$, same methodology that was followed in the present work. In this way, the primary compression SS is always (1 111 ) [1 01$]$, whereas the secondary SS for this state can be either $\left(\begin{array}{lll}1 & 1 & 1\end{array}\right)\left[\begin{array}{lll}1 & 1 & 0\end{array}\right],\left(\begin{array}{lll}1 & 1 & 1\end{array}\right)\left[\begin{array}{llll}1 & 0 & 1\end{array}\right]$ or $\left(\begin{array}{lll}1 & 1 & 1\end{array}\right)\left[\begin{array}{lll}0 & 1 & 1\end{array}\right]$. Moreover, the variants of each PAG were numbered according to a global coordinate system. To prove the premise by Miyamoto et al., the average area percentages $\left(\mathrm{AP}_{V i}\right)$ of each of the variants of the selected EBSD maps mentioned in Section III-B., numbered according to Table II, were estimated by Eq. [7] and are shown in Figure 9.

$$
\mathrm{AP}_{V i}=\frac{\sum_{j=1}^{N_{t}} \mathrm{AP}_{V i, j}}{N_{t}}
$$

The expected values of $\mathrm{AP}_{V i}$ for each of the variants, in a random distribution ( $\mathrm{AP}_{V i}$ equal to $4.2 \mathrm{pct}$ for $i=1 \ldots 24)$, is depicted by a horizontal dashed line; the Ps are identified by shadowed areas and the color of the markers depends on the BG to which the variant 
Table III. Bishop and Hill Slip Systems, Corresponding KS Rotation Axes and Rotation Axes of the Experimental OR Determined in This Work

\begin{tabular}{|c|c|c|c|c|c|}
\hline BH SS & Slip Plane & Slip Direction & KS OR Rotation Axis & Experimental OR Rotation Axis & Experimental Variant \\
\hline$\overline{\mathrm{aI}}$ & $\left(\begin{array}{lll}1 & 1 & 1\end{array}\right)$ & {$\left[\begin{array}{lll}0 & 1 & 1\end{array}\right]$} & {$[2 \overline{1} 1]$} & {$\left[\begin{array}{lll}0.831 & \overline{0.379} & \overline{0.408}\end{array}\right.$} & $V 5$ \\
\hline -aI & & {$\left[\begin{array}{lll}0 & \overline{1} & 1\end{array}\right]$} & {$\left[\begin{array}{lll}2 & 1 & 1\end{array}\right]$} & {$\left[\begin{array}{lll}\overline{0.831} & 0.408 & 0.379\end{array}\right]$} & $V 2$ \\
\hline aII & & {$\left[\begin{array}{lll}1 & 0 & 1\end{array}\right]$} & {$\left[\begin{array}{lll}1 & 2 & 1\end{array}\right]$} & {$\left[\begin{array}{lll}\overline{0.408} & 0.831 & \overline{0.379}\end{array}\right]$} & $V 1$ \\
\hline -aII & & {$\left[\begin{array}{lll}1 & 0 & 1\end{array}\right]$} & {$\left[\begin{array}{lll}1 & \overline{2} & 1\end{array}\right]$} & {$\left[\begin{array}{lll}0.379 & \overline{0.831} & 0.408\end{array}\right]$} & $V 4$ \\
\hline aIII & & {$\left[\begin{array}{lll}1 & 1 & 0\end{array}\right]$} & {$\left[\begin{array}{lll}1 & 1 & 2\end{array}\right]$} & {$\left[\begin{array}{lll}\overline{0.379} & \overline{0.408} & 0.831\end{array}\right]$} & $V 3$ \\
\hline -aIII & & {$\left[\begin{array}{lll}1 & 1 & 0\end{array}\right]$} & {$\left[\begin{array}{lll}1 & 1 & 2\end{array}\right]$} & {$\left[\begin{array}{lll}0.408 & 0.379 & 0.831\end{array}\right]$} & $V 6$ \\
\hline bI & $\left(\begin{array}{lll}1 & 1 & \overline{1}\end{array}\right)$ & {$\left[\begin{array}{lll}0 & 1 & 1\end{array}\right]$} & {$\left[\begin{array}{lll}2 & 1 & \overline{1}\end{array}\right]$} & {$\left[\begin{array}{ll}\overline{0.831} & 0.379 \overline{0.408}\end{array}\right]$} & $V 19$ \\
\hline$-b I$ & & {$\left[\begin{array}{lll}0 & 1 & 1\end{array}\right]$} & {$\left[\begin{array}{lll}2 & 1 & 1\end{array}\right]$} & {$\left[\begin{array}{llll}0.831 & \overline{0.408} & 0.379\end{array}\right]$} & $V 22$ \\
\hline bII & & {$\left[\begin{array}{lll}1 & 0 & 1\end{array}\right]$} & {$\left[\begin{array}{ll}1 & \overline{2} \\
1\end{array}\right]$} & {$\left[\begin{array}{llll}0.408 & \overline{0.831} & 0.379\end{array}\right]$} & $V 21$ \\
\hline -bII & & {$\left[\begin{array}{lll}1 & 0 & 1\end{array}\right]$} & {$\left[\begin{array}{lll}1 & 2 & 1\end{array}\right]$} & {$\left[\begin{array}{llll}\overline{0.379} & 0.831 & 0.408\end{array}\right]$} & $V 24$ \\
\hline bIII & & {$\left[\begin{array}{lllll}1 & 1 & 0\end{array}\right]$} & {$\left[\begin{array}{lll}1 & 1 & 2\end{array}\right]$} & {$\left[\begin{array}{lll}0.379 & 0.408 & 0.831\end{array}\right]$} & $V 23$ \\
\hline -bIII & & {$\left[\begin{array}{lll}1 & 1 & 0\end{array}\right]$} & {$[\overline{1} \overline{1} \overline{2}]$} & $[\overline{0.408} \overline{0.379} \overline{0.831}]]$ & $V 20$ \\
\hline cI & $\left(\begin{array}{lll}1 & 1 & 1\end{array}\right)$ & {$\left[\begin{array}{lll}0 & 1 & 1\end{array}\right]$} & {$\left[\begin{array}{lll}2 & 1 & 1\end{array}\right]$} & {$\left[\begin{array}{llll}0.831 & 0.379 & 0.408\end{array}\right]$} & $V 16$ \\
\hline$-\mathrm{cI}$ & & {$\left[\begin{array}{lll}0 & 1 & 1\end{array}\right]$} & {$\left[\begin{array}{lll}2 & 1 & 1\end{array}\right]$} & {$[\overline{0.831} \overline{0.408} \overline{0.379}]$} & $V 13$ \\
\hline cII & & {$\left[\begin{array}{lll}1 & 0 & 1\end{array}\right]$} & {$\left[\begin{array}{lll}\overline{1} & 2 & 1\end{array}\right]$} & {$\left[\begin{array}{lll}\overline{0.408} & \overline{0.831} & 0.379\end{array}\right]$} & $V 14$ \\
\hline -cII & & {$\left[\begin{array}{lll}1 & 0 & 1\end{array}\right]$} & {$\left[\begin{array}{lll}1 & 2 & 1\end{array}\right]$} & {$\left[\begin{array}{llll}0.379 & 0.831 & \overline{0.408}\end{array}\right]$} & $V 17$ \\
\hline cIII & & {$\left[\begin{array}{lll}1 & 1 & 0\end{array}\right]$} & {$\left[\begin{array}{lll}\overline{1} & 1 & 2\end{array}\right]$} & {$\left[\begin{array}{lll}\overline{0.379} & 0.408 & \overline{0.831}\end{array}\right]$} & $V 18$ \\
\hline -cIII & & {$\left[\begin{array}{lll}1 & 1 & 0\end{array}\right]$} & {$[1 \overline{1} 2]$} & {$\left[\begin{array}{lll}0.408 & \overline{0.379} & 0.831\end{array}\right]$} & $V 15$ \\
\hline $\mathrm{dI}$ & $(1 \overline{1} 1)$ & {$\left[\begin{array}{lll}0 & 1 & 1\end{array}\right]$} & {$\left[\begin{array}{lll}2 & 1 & 1\end{array}\right]$} & $[\overline{0.831} \overline{0.379} 0.408]]$ & $V 12$ \\
\hline$-d I$ & & {$\left[\begin{array}{lll}0 & 1 & 1\end{array}\right]$} & {$\left[\begin{array}{lll}2 & 1 & 1\end{array}\right]$} & {$\left[\begin{array}{lll}0.831 & 0.408 & 0.379\end{array}\right]$} & $V 9$ \\
\hline dII & & {$\left[\begin{array}{lll}1 & 0 & 1\end{array}\right]$} & {$\left[\begin{array}{lll}1 & 2 & 1\end{array}\right]$} & {$\left[\begin{array}{lll}0.408 & 0.831 & 0.379\end{array}\right]$} & $V 10$ \\
\hline$-\mathrm{dII}$ & & {$\left[\begin{array}{lll}1 & 0 & 1\end{array}\right]$} & {$\left[\begin{array}{lll}1 & 2 & 1\end{array}\right]$} & {$\left[\begin{array}{lll}\overline{0.379} & \overline{0.831} & \overline{0.408}\end{array}\right]$} & $V 7$ \\
\hline dIII & & {$\left[\begin{array}{lll}1 & 1 & 0\end{array}\right]$} & {$\left[\begin{array}{lll}1 & 1 & 2\end{array}\right]$} & {$[0.379 \overline{0.408} \overline{0.831}]$} & $V 8$ \\
\hline -dIII & & {$\left[\begin{array}{lll}1 & 1 & 0\end{array}\right]$} & {$\left[\begin{array}{lll}1 & 1 & 2\end{array}\right]$} & {$\left[\begin{array}{lll}0.408 & 0.379 & 0.831\end{array}\right]$} & $V 11$ \\
\hline
\end{tabular}

The variants to which the experimental OR rotation axes correspond, according to Table II, can be also found.

belongs. The obtained results agree with the ones of Miyamoto et al., as it is shown that variants in P1 and $\mathrm{P} 3$, specially $V 4$ and $V 16$, are more frequent as $T_{\text {def }}$ decreases. Moreover, as $T_{\text {def }}$ is lowered, the values of $\mathrm{AP}_{V i}$ corresponding to the variants in $\mathrm{P} 2$ and $\mathrm{P} 4$ decreased way below 4.2 pct, except for the values corresponding to $V 9$ and $V 21$, which remain close to 4.2 pct.

These results show that the selection of variants can be better described in terms of their belonging to packets, if variants are defined according to a global reference frame, rather than by the activation of certain Bain groups. The fact that variants corresponding to the packets $\mathrm{P} 1$ and $\mathrm{P} 3$ are more prone to appear suggests that the phenomena might have to do with the effect of deformation mechanisms in $\gamma_{\text {def }}$. The next subsection reviews some of the models explaining variant selection based on deformation mechanisms.

\section{Mechanisms governing variant selection}

Sum and Jonas ${ }^{[15]}$ proposed that the presence of dislocations in prior austenite previously subjected to deformation (in their case, through rolling) is directly related to the occurrence of variant selection in martensitic structures. They proposed a model based on the SS slip activity and they claimed that their model was able to predict global transformation textures in the presence of variant selection accurately. This model relies on the one-to-one correspondence between the Bishop and Hill (BH) SS of austenite, $\left\{\begin{array}{lll}1 & 1\end{array}\right\}\langle 110\rangle,{ }^{[44,45]}$ and the twenty-four variants of the KS OR. The KS OR was represented by 90 deg rotations about all austenite $\langle 112\rangle$ axes, which were equal to the cross product of the corresponding slip direction and slip plane normal. The model by Sum and Jonas was later verified to be accurate for hot-rolled austenite by other authors. ${ }^{[46-48]}$ In addition, the model was also extrapolated to the NW-OR by considering the presence of partial dislocations ${ }^{[42]}$ which was proven to accurately predict the global textures of martensite and bainite grown from hot-rolled austenite. ${ }^{[42,48]}$ Gong et al. ${ }^{[9]}$ used a simplification of this model to explain variant selection in ausformed nanobainite with a NW-OR, by analyzing three PAGs in which they showed that the formed variants were the ones corresponding to the austenite SS with the highest Schmid factor (SF). Note that the deformation was applied through compression, as in the present work. Table III includes all BH SS and their correspondence with the KS rotation axes. The model states that the nucleation of variants is affected by the dislocations remaining on the slip planes; some of them are active dislocations, and some of them (called unstressed dislocations) can be formed by in-plane reactions involving at least one active dislocation. 
A study homologous to Gong et al.'s ${ }^{[9]}$ was performed for the current microstructures by using the reconstructed $\gamma / \gamma_{\text {def }}$ data and the $\alpha_{B}$ data from EBSD. Although, in this case, the OR is considered to be neither the KS nor NW OR. Instead, a rotation close to $<$ axis $>90$ deg and in agreement with the experimental OR was determined, according to Bishop and Hill. ${ }^{[44,45]}$ In this case, the rotation meeting this criterion is $\langle 0.3790 .4080 .831\rangle 90.20 \mathrm{deg}$. In this way, each of the 24 crystallographic variants was associated with a slip system so that the experimental $\mathrm{OR}$ rotation axis is as close as possible to the cross product of the slip direction and the slip plane normal. For the given rotation, the result of such cross product is only misaligned by 1.88 deg with respect to the calculated rotation axis. The experimental OR rotation axes that corresponds to each of the BH SS are also included in Table III.

For the selected EBSD maps, for each variant $i$, the Schmid Factor (SF) Weighted Average $\left(\mathrm{SF}_{i-\mathrm{WA}}\right)$ were calculated as follows:
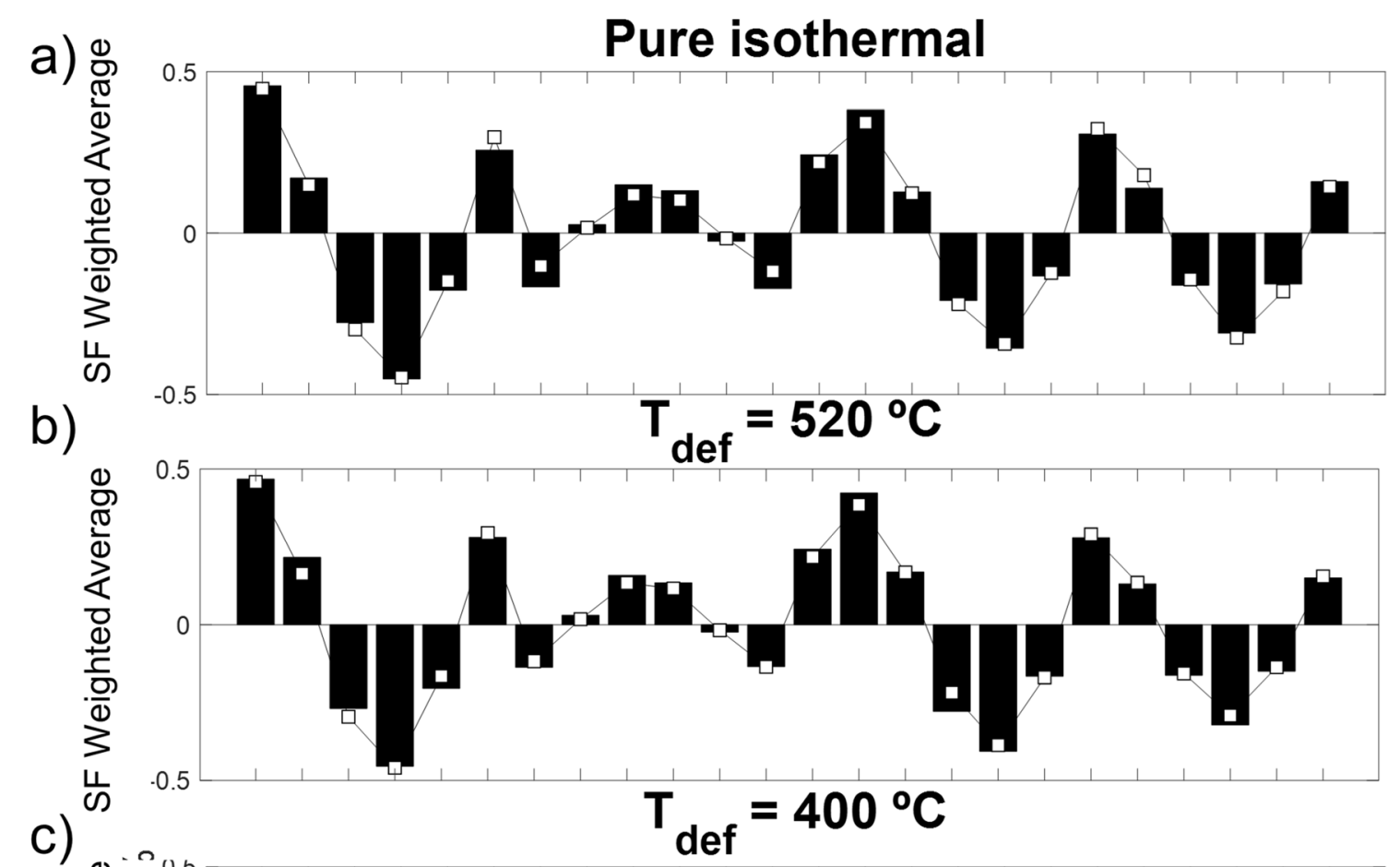

C)

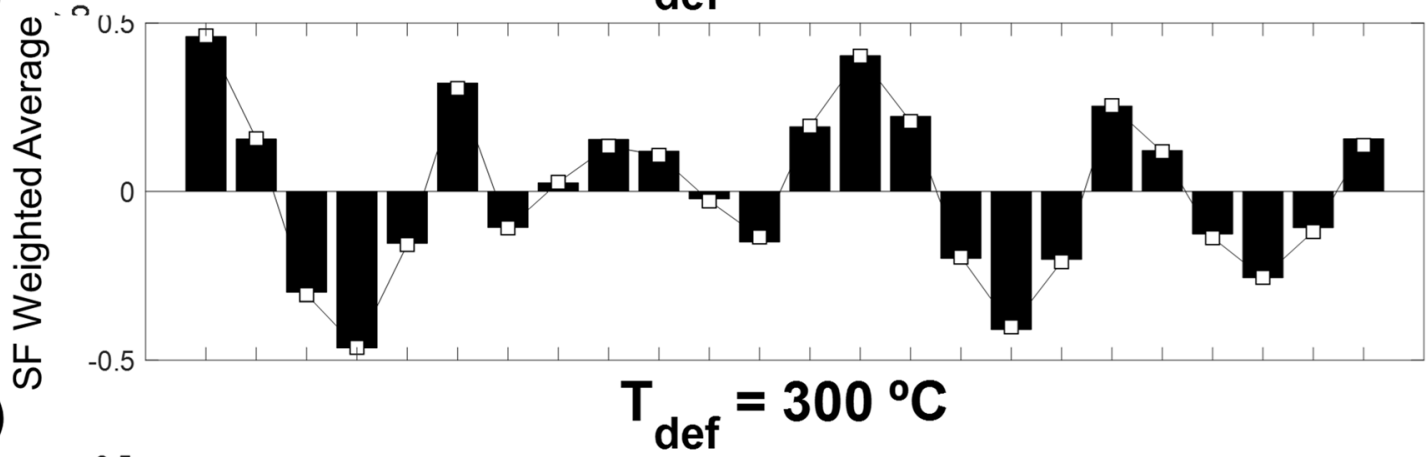

d)

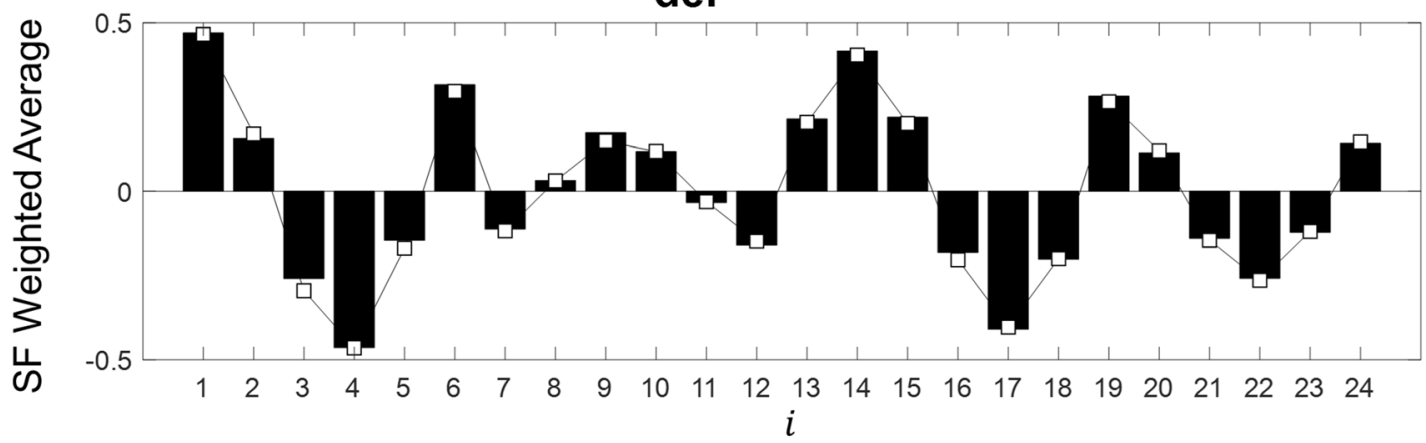

Fig. 10- $\mathrm{SF}_{i-\mathrm{WA}}$ (black bars) and $\mathrm{SF}_{i-\mathrm{NVS}}$ (white squares) as a function of $i$ for the EBSD maps representative of the global texture. Data correspond to: $(a)$ pure isothermal treatment; $(b)$ ausforming at $520{ }^{\circ} \mathrm{C} ;(c)$ ausforming at $400{ }^{\circ} \mathrm{C}$ and $(d)$ ausforming at $300{ }^{\circ} \mathrm{C}$. 


$$
\mathrm{SF}_{i-\mathrm{WA}}=\frac{\sum_{j=1}^{N_{t}} A_{V i, j} \cdot \mathrm{SF}_{i, j}}{\sum_{j=1}^{N_{t}} A_{P A G_{-} j}}
$$

where $\mathrm{SF}_{i, j}$ is the $\mathrm{SF}$ of the $\mathrm{BH} \mathrm{SS}$ associated with the $i$ th variant in the $P A G_{-} j$. These $\mathrm{SF}_{i-\mathrm{WA}}$ values were compared to the ones that would be obtained if no variant selection occurred $\left(\mathrm{SF}_{i-\mathrm{NVS}}\right)$, calculated as:

$$
\mathrm{SF}_{i-\mathrm{NVS}}=\frac{\sum_{j=1}^{N_{t}}\left(A_{P A G_{j}} \cdot \mathrm{SF}_{i, j}\right)}{24 \cdot \sum_{j=1}^{N_{t}} A_{P A G_{-j}}}
$$

Note that, because the $\gamma / \gamma_{\text {def }}$ texture is not random, not all $\mathrm{SF}_{i-\mathrm{NVs}}$ values are equal. Figure 10 shows $\mathrm{SF}_{i-\mathrm{WA}}$ and $\mathrm{SF}_{i-\mathrm{NVS}}$ as a function of the variant number $i$.

Since variants were indexed with respect to the global coordinate system, as explained before, the sign of both $\mathrm{SF}_{i-\mathrm{WA}}$ and $\mathrm{SF}_{i-\mathrm{NVS}}$ for a given variant $i$ is always the same and there are also some trends with respect to their intensities. Therefore, $\mathrm{SF}_{1, j}$ is always the highest $\mathrm{SF}_{i, j}$ for any PAG $P A G_{-} j$, followed by $\mathrm{SF}_{6, j}, \mathrm{SF}_{14, j}$ and $\mathrm{SF}_{19, j}$, not always in the same order. The lowest $\mathrm{SF}_{i, j}$ is always $\mathrm{SF}_{4, j}$, which has the most negative value for any PAG $P A G_{-} j$, followed by $\mathrm{SF}_{3, j}, \mathrm{SF}_{17, j}$ and $\mathrm{SF}_{22, j}$, in a different order depending on the $\gamma / \gamma_{\text {def }}$ orientation. According to the previously explained study by Gong et al. ${ }^{[9]}$ variants associated with highly active SS should appear in a higher fraction. However, neither $\mathrm{AP}_{V 1} \mathrm{AP}_{V 6}, \mathrm{AP}_{V 14}$ nor $\mathrm{AP}_{V 19}$ exceed 4.2 pct in any case, see Figure 9. In addition, as previously shown, variant selection in ausformed samples led to an increase of $\mathrm{AP}_{V 4}$ and $\mathrm{AP}_{V 16}$, especially, whose corresponding $\mathrm{SF}_{4-\mathrm{WA}}$ and $\mathrm{SF}_{16-\mathrm{WA}}$ is negative, i.e., the corresponding SS (-aII and cI, respectively) are not active.

Therefore, the simplified model by Gong et al. ${ }^{[9]}$ cannot explain the present experimental results, which could be due to the fact that the accuracy of the model is not good and, thus, applying another dislocations-related model — such as Sum and Jonas ${ }^{[15]}$ —would be enough to explain the phenomena. Another possible explanation can be that the reason lying underneath the variant selection is not related to dislocations but to residual stresses remaining in the microstructure. In this sense, some authors have concluded that macroscopic stresses do not play a role in variant selection during ausforming. ${ }^{[14,49]}$ However some other works have argued that variant selection in plastically deformed austenite could be the result of intergranular or intragranular residual stresses. Such stresses would interact with the volume and shear strains associated with the $\alpha_{\mathrm{B}}$ plates as it occurs during martensitic/bainitic transformations subjected to stress. ${ }^{[16,17]} \mathrm{A}$ further study is required in order to elucidate whether either dislocations or residual stresses govern the selection of crystallographic variants during ausforming processes.

\section{CONCLUSION}

The orientation relationship between $\gamma / \gamma_{\text {def }}$ and the $\alpha_{\mathrm{B}}$, close to the one evidenced by Greninger-Troiano, is not altered by plastic deformation in the studied steel. Possible differences may be due to the deformation of the crystal lattice.

The austenite texture is not modified during the bainitic transformation in ausforming treatments, indicating that possible inhomogeneus plastic deformation coming from the $\gamma$ polycrystalline structure does not affect significantly the volume fraction of $\alpha_{\mathrm{B}}$. As expected, the austenite texture does not change during the bainitic transformation in pure isothemal treatments (without prior deformation) either.

A variant selection phenomenon is detected for the microstructure obtained by a pure isothermal treatment. This variant selection is due to a texture memory effect: the global texture of the $\alpha_{\mathrm{B}}$ is slightly inherited from the global texture of the $\alpha$ present in the as-received material, hot-rolled bars.

The bainitic transformations occurred during ausforming treatments are also controlled by variant selection phenomena, which are more pronounced as the deformation temperature decreases. The mechanisms driving variant selection during the pure isothermal treatment still govern the transformation, although they are cancelled out by new mechanisms related to the applied plastic deformation.

A quantitative study has revealed that variants are not selected based on their Bain group, neither during the pure isothermal nor during the ausforming treatments, as opposed to what was suggested by other authors. For an EBSD indexing convention based on the global coordinate frame, where the sample $Z$-axis lies within the triangle delimited by the $\gamma / \gamma_{\text {def }}$ crystal directions $\left[\begin{array}{lll}0 & 0 & 1\end{array}\right]-\left[\begin{array}{ll}1 \\ 1\end{array}\right.$ $\left.\begin{array}{ll}1 & 1\end{array}\right]-\left[\begin{array}{lll}0 & 1 & 1\end{array}\right]$, it has been observed that the variants corresponding to certain packets are more prone to appear, in good agreement with Miyamoto et al. ${ }^{[11]}$

The simplification of the model of Sum and Jonas applied by Gong et al., which links every crystallographic variant with a given $\gamma / \gamma_{\text {def }}$ SS, predicting that variants corresponding to SS with the highest SF are more favored to form, is not able to explain the observed variant selection. A further study is required in order to make conclusions on whether either dislocations or residual stresses govern the selection of crystallographic variants during ausforming processes

\section{ACKNOWLEDGMENTS}

The authors acknowledge Sidenor for providing them with the material, Irene Llorente (from the X-Ray Diffraction lab at CENIM) for her support to analyze the XRD results, in addition to the support of the Metallography and Phase Transformations labs (CENIM) and the Electron Microscopy Service facility (Polytechnic School of Valencia).

\section{FUNDING}

Open Access funding enabled and organized by Projekt DEAL. This work was supported by the European Research Fund for Coal and Steel under the 
Contract RFCS-2019-899482; the German Research Foundation (DFG) under the project 411091845 and the German Academic Exchange Service (DAAD) under the funding program Research Grants-ShortTerm Grants (57440917), personal ref 91710971.

\section{CONFLICT OF INTEREST}

On behalf of all authors, the corresponding author states that there is no conflict of interest.

\section{OPEN ACCESS}

This article is licensed under a Creative Commons Attribution 4.0 International License, which permits use, sharing, adaptation, distribution and reproduction in any medium or format, as long as you give appropriate credit to the original author(s) and the source, provide a link to the Creative Commons licence, and indicate if changes were made. The images or other third party material in this article are included in the article's Creative Commons licence, unless indicated otherwise in a credit line to the material. If material is not included in the article's Creative Commons licence and your intended use is not permitted by statutory regulation or exceeds the permitted use, you will need to obtain permission directly from the copyright holder. To view a copy of this licence, visit http://creativecommons.org/ licenses/by/4.0/.

\section{REFERENCES}

1. H.K.D.H Bhadeshia: Bainite in Steels: Theory and Practice, CRC Press, Boca Raton, 2019.

2. W. Gong, Y. Tomota, M.S. Koo, and Y. Adachi: Scr. Mater., 2010, vol. 63, pp. 819-22.

3. J. Cornide, C. Garcia-Mateo, C. Capdevila, and F.G. Caballero: $J$. Alloys Compd., 2013, vol. 577, pp. S43-47.

4. S.B. Singh and H.K.D.H. Bhadeshia: Mater. Sci. Eng. A, 1998, vol. 245 , pp. $72-79$.

5. J. Yang, C. Huang, and W. Hsieh: Mater. Trans. JIM, 1996 , vol. 37, pp. 579-85.

6. S. Chatterjee, H.S. Wang, J.R. Yang, and H.K.D.H. Bhadeshia: Mater. Sci. Technol., 2006, vol. 22, pp. 641-44.

7. P.H. Shipway and H.K.D.H. Bhadeshia: Mater. Sci. Technol., 1995, vol. 11, pp. 1116-28.

8. A. Eres-Castellanos, F.G. Caballero, and C. Garcia-Mateo: Acta Mater., 2020, vol. 189 , pp. 60-72.

9. W. Gong, Y. Tomota, Y. Adachi, A.M. Paradowska, J.F. Kelleher, and S.Y. Zhang: Acta Mater., 2013, vol. 61, pp. 4142-54.

10. A. Eres-Castellanos, L. Morales-Rivas, A. Latz, F.G. Caballero, and C. Garcia-Mateo: Mater. Charact., 2018, vol. 145, pp. 371-80.

11. G. Miyamoto, N. Iwata, N. Takayama, and T. Furuhara: J. Alloys Compd., 2013, vol. 577, pp. S528-S532.

12. J. He, J. Du, W. Zhang, C. Zhang, Z.-G. Yang, and H. Chen: Metall. Mater. Trans. A, 2019, vol. 50A, pp. 540-46.

13. H. Guo, X. Feng, A. Zhao, Q. Li, and M. Chai: J. Mater. Res. Technol., 2020, vol. 9, pp. 1593-1605.

14. A.A. Shirzadi, H. Abreu, L. Pocock, D. Klobcar, P.J. Withers, and H.K.D.H. Bhadeshia: Int. J. Mater. Res., 2009, vol. 100, pp. $40-45$.

15. M. Sum and J.J. Jonas: Texture Stress. Microstruct., 1999, vol. 31, pp. 187-215.
16. S. Kundu: Mater. Sci. Eng. A, 2009, vol. 516, pp. 290-96.

17. Y.D. Wang, R.L. Peng, X.-L. Wang, and R.L. McGreevy: Acta Mater., 2002, vol. 50, pp. 1717-34.

18. H.J. Bunge: Texture Anal. Mater. Sci., 1982.

19. F. Bachmann, R. Hielscher, and H. Schaeben: in Solid State Phenomena, vol. 160, Trans Tech Publ, 2010, pp. 63-68.

20. H. Hu: in Texture, vol. 1, Hindawi, 1970.

21. E.C. Bain and N.Y. Dunkirk: Trans. AIME, 1924, vol. 70, pp. 25-47.

22. G. Kurdjumow and G. Sachs: Zeitschrift fur Phys., 1930, vol. 64, pp. 325-43.

23. N. Yoshinaga, K. Ushioda, A. Itami, and O. Akisue: ISIJ Int., 1994, vol. 34, pp. 33-42.

24. L. Ryde, D. Artymowicz, and W.B. Hutchinson: in ICOTOM 12: 12 th International Conference on Textures of Materials, 1999, pp. 1031-36.

25. A. Kaijalainen, P. Suikkanen, and D.A. Porter: in IOP Conference Series: Materials Science and Engineering, vol. 82, IOP Publishing, 2015, p. 12058.

26. F. Fang, Y. Zhao, L. Zhou, X. Hu, Z. Xie, and J. Jiang: Mater. Sci. Eng. A, 2014, vol. 618, pp. 505-10.

27. F.M. Castro Cerda, B. Schulz, S. Papaefthymiou, A. Artigas, A. Monsalve, and R.H. Petrov: Metals, 2016, vol. 6, p. 321.

28. N. Yoshinaga, H. Inoue, K. Kawasaki, and L. Kestens: Mater. Trans., 2007, vol. 48, pp. 2036-42.

29. C. Cayron, F. Barcelo, and Y. De Carlan: Scr. Mater., 2011, vol. 64 , pp. 103-06.

30. A.B. Greninger and A.R. Troiano: JOM, 1949, vol. 1, pp. 590-98.

31. P.M. Kelly, A. Jostsons, and R.G. Blake: Acta Metall. Mater., 1990, vol. 38, pp. 1075-81.

32. C. Cayron: J. Appl. Crystallogr., 2007, vol. 40, pp. 1183-88.

33. T. Nyyssönen, P. Peura, and V.T. Kuokkala: Metall. Mater. Trans. A, 2018, vol. 49A, pp. 6426-41, https://doi.org/10.1007/ s11661-018-4904-9.

34. S.A. Filippov and N.Y. Zolotorevsky: Mater. Lett., 2018, vol. 214, pp. 130-33.

35. G.V. Smith and R.F. Mehl: Trans. AIME, 1942, vol. 150, p. 14.

36. N.Y. Zolotorevsky, S.N. Panpurin, A.A. Zisman, and S.N. Petrov: Mater. Charact., 2015, vol. 107, pp. 278-82.

37. H.C.H. Carpenter and S. Tamura: Proc. R. Soc. Lond. Ser. A, 1926, vol. 113, pp. $28-43$.

38. H.K.D.H. Bhadeshia and A.R. Waugh: Acta Metall., 1982, vol. 30 , pp. $775-84$.

39. L.C. Chang and H.K.D.H. Bhadeshia: Mater. Sci. Eng. A, 1994, vol. 184, pp. L17-L19.

40. E. Schmid and W. Boas: in Kristallplastizität, Springer, 1935, pp. $15-24$.

41. S. Kundu and H. Bhadeshia: Scr. Mater., 2006, vol. 55, pp. $779-81$.

42. J.J. Jonas, Y. He, and S. Godet: Scr. Mater., 2005, vol. 52, pp. $175-79$

43. H.K.D.H. Bhadeshia, S.A. David, J.M. Vitek, and R.W. Reed: Mater. Sci. Technol., 1991, vol. 7, pp. 686-98.

44. J.F.W. Bishop and R. Hill: Lond. Edinb. Dublin Philos. Mag. J. Sci., 1951, vol. 42, pp. 414-27.

45. J.F.W. Bishop and R. Hill: Lond. Edinb. Dublin Philos. Mag. J. Sci., 1951, vol. 42, pp. 1298-1307.

46. N.J. Wittridge, J.J. Jonas, and J.H. Root: Metall. Mater. Trans. A, 2001, vol. 32A, p. 889.

47. J.J. Jonas and N.J. Wittridge: in Multiscale Phenomena in Plasticity: From Experiments to Phenomenology, Modelling and Materials Engineering, Springer, 2000, pp. 143-56.

48. Y. He: Grain-Scale Characterization of FCC/BCC Correspondence Relations and Variant Selection, 2005.

49. M. Humbert, F. Wagner, W.P. Liu, C. Esling, and H.J. Bunge: in Proc. 8th Int. Conf. on 'Textures of Materials, 1988.

Publisher's Note Springer Nature remains neutral with regard to jurisdictional claims in published maps and institutional affiliations. 